\title{
Disentangling the influence of local and remote anthropogenic aerosols on South Asian monsoon daily rainfall characteristics
}

\author{
Deepti Singh ${ }^{1,2}\left(\right.$ D) Massimo Bollasina ${ }^{3} \cdot$ Mingfang Ting $^{2,4} \cdot$ Noah S. Diffenbaugh $^{5,6}$
}

Received: 12 April 2018 / Accepted: 19 October 2018

(c) Springer-Verlag GmbH Germany, part of Springer Nature 2018

\begin{abstract}
Wet and dry periods within the South Asian summer monsoon season can have acute societal impacts. Recent studies have identified changes in daily rainfall characteristics of the monsoon, but the underlying causes are poorly understood. In particular, although the dominant role of anthropogenic aerosols in shaping historical changes in seasonal-mean monsoon rainfall has been documented, their influence on daily-scale rainfall remains unconstrained. Using an ensemble of single-forcing climate simulations, we find that anthropogenic aerosols have a stronger influence on late-twentieth century changes in the frequency of wet events, dry events and rainless days, compared with other climate forcings. We also investigate the role of aerosol-cloud interactions ("indirect effects") in the total aerosol response, and the contribution of aerosols emitted from South Asia versus from remote sources. Based on additional simulations with the GFDL-CM3 climate model, we find that the simulated aerosol response over South Asia is largely associated with aerosol-indirect effects. In addition, local aerosols suppress wet-event frequency and enhance dry-event frequency over eastern-central India, where increases in aerosol loading are the largest. Remote aerosols cause a north-south dipole pattern of change in mean rainfall over India and fewer rainless days over western India. However, the overall spatial response of South Asian rainfall characteristics to total aerosol forcing is substantially influenced by the combined non-linear climate response to local and remote aerosols. Together, our results suggest that understanding the influence of different aerosol emissions trajectories on the regional climate dynamics is critical for effective climate-risk management in this populated, vulnerable region.
\end{abstract}

Keywords South Asian Monsoon · Anthropogenic aerosols · Local and remote aerosols · Daily-scale precipitation

Electronic supplementary material The online version of this article (https://doi.org/10.1007/s00382-018-4512-9) contains supplementary material, which is available to authorized users.

Deepti Singh

deepti.singh@wsu.edu

1 School of the Environment, Washington State University, 98686 Vancouver, WA, USA

2 Lamont Doherty Earth Observatory, Columbia University, New York City, NY, USA

3 School of Geosciences, University of Edinburgh, Edinburgh, UK

4 Department of Earth and Environmental Sciences, Columbia University, New York City, NY, USA

5 Department of Earth System Science, Stanford University, Stanford, CA, USA

6 Woods Institute for the Environment, Stanford University, Stanford, CA, USA

\section{Introduction}

Variations in the timing, spatial distribution and characteristics of the South Asian summer monsoon rainfall can affect the economy, agriculture, ecosystems, human health, and water resources of the world's most densely populated region (Gadgil and Kumar 2006; Gadgil and Gadgil 2006). Subseasonal monsoon variability - which manifests as wet and dry periods - is a critical factor in determining monsoonal impacts via, for example, intense rainfall and droughts that can adversely affect agricultural output and farmer livelihoods (Gornall et al. 2010). Numerous studies have documented changes in the historical subseasonal rainfall characteristics over India on a range of spatial scales, including changes in the frequency of wet and dry spells over different sub-regions (Guhathakurta and Rajeevan 2008; Dash et al. 2009; Rajeevan et al. 2010; Guhathakurta et al. 2011; Singh et al. 2014; Vinnarasi and Dhanya 2016; Krishnan et al. 2016; Roxy et al. 2017). 
Historical Emissions

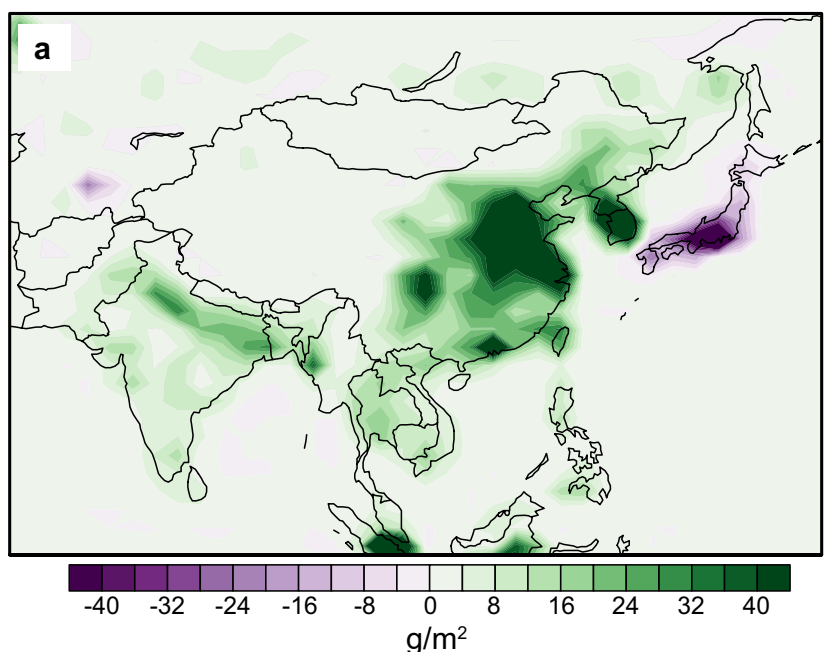

Net Surface Radiation

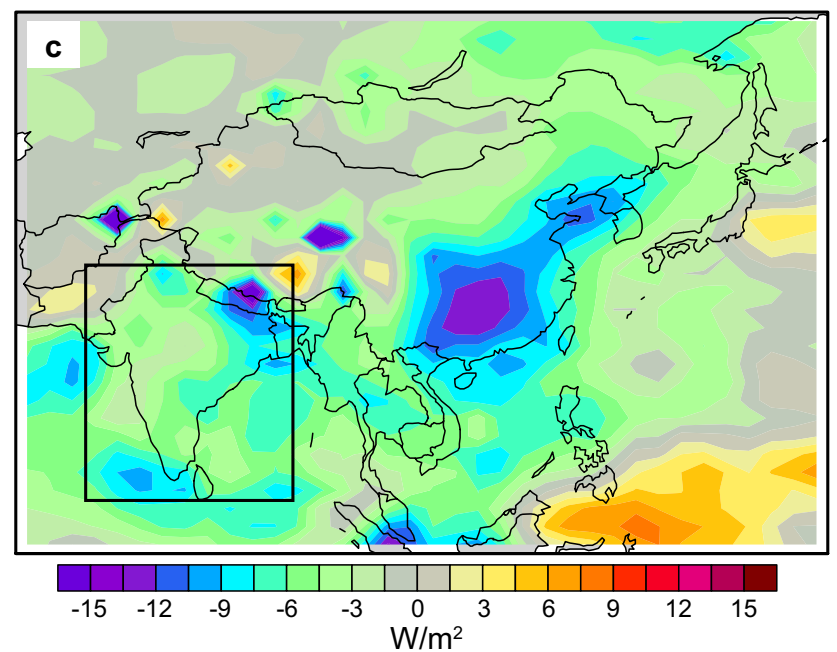

Fig. 1 Historical Emissions and Forcing Changes: Changes in mean peak-monsoon season (July-August) a anthropogenic aerosol emissions, $\mathbf{b}$ aerosol optical depth (AOD) in the ALL-Forcing simulation, $\mathbf{c}$ net surface radiation, and $\mathbf{d}$ net top of the atmosphere (TOA) radiation, between 1951-1975 and 1976-2000, based on the GFDL-CM3

On a global-scale, studies have found a strong anthropogenic contribution to the observed changes in daily rainfall extremes (Min et al. 2011; Fischer and Knutti 2015; Diffenbaugh et al. 2017). On a regional-scale, Lin et al. (2018) suggest that anthropogenic aerosols have had a substantial influence on the large-scale pattern of historical changes in extreme heavy rainfall events over Asia. However, the influence of individual anthropogenic forcings-including greenhouse gases (GHG) and anthropogenic aerosols-on these historical changes over South Asia have not been distinguished. Studies suggest that changes in aerosol forcing might have a stronger effect on precipitation than changes in GHG in coming decades, if the world progresses on a low

\section{Aerosol Optical Depth}

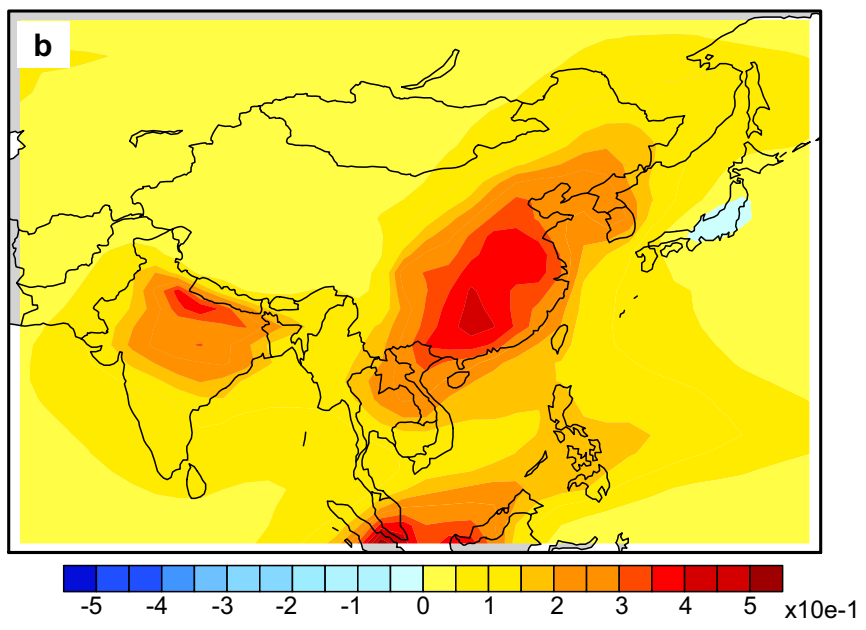

\section{Net TOA Radiation}

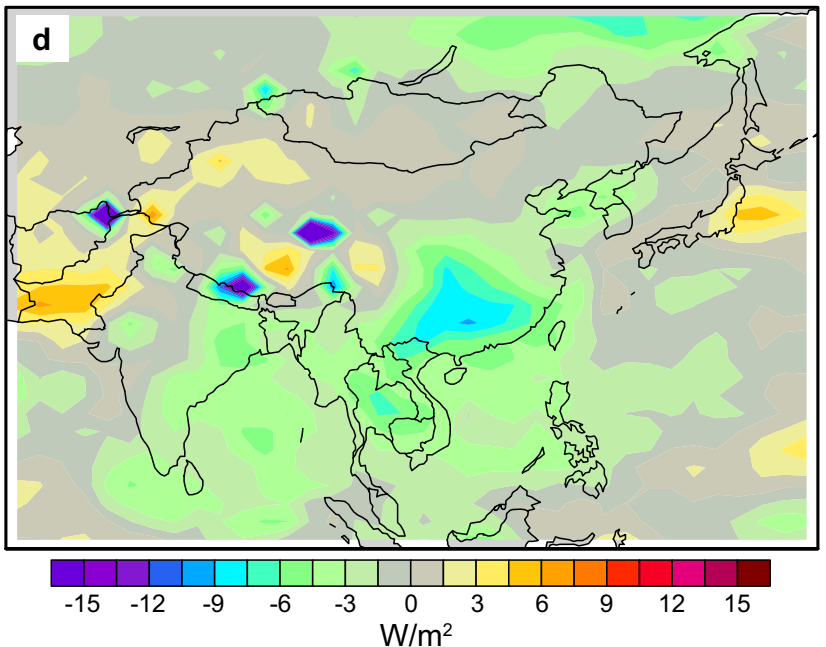

model. Historical emissions that are input to the model are from the CMIP5 standard gridded dataset [Lamarque et al. (2010)]. The black rectangle in (c) encompasses the domain used in the analysis of spatial correlations $\left(6-32^{\circ} \mathrm{N}, 68-90^{\circ} \mathrm{E}\right)$

GHG emissions pathway (Lin et al. 2016). Rainfall extremes have different sensitivities to GHGs and anthropogenic aerosols (Lin et al. 2016), and different concentrations of aerosols can either enhance or inhibit rainfall (Rosenfeld et al. 2008; Koren et al. 2014; Fan et al. 2013, 2016). Given that emissions of GHGs and aerosols will likely exhibit different pathways in the future (van Vuuren et al. 2011), it is important to understand whether and how changes of each individual forcing have influenced subseasonal rainfall events during the historical period.

Unlike GHGs, aerosols concentrations and their historical trends have large regional variations (Fig. 1). Anthropogenic aerosols from fossil fuel burning-particularly 
sulfate aerosols and black carbon-have increased rapidly throughout the late twentieth century over South and East Asia (Fig. 1a, b). During the same period, aerosol loadings decreased over North America and Europe, following strict air-quality regulations (Smith et al. 2011; Granier et al. 2011; Lu et al. 2011). The increases in aerosol loading over Asia are associated with large negative radiative forcing over the region relative to the preindustrial period (e.g., Ramanathan et al. 2001; Bollasina et al. 2011). Simulations with the GFDL-CM3 model (Donner et al. 2011) suggest that over the second half of the twentieth century, the net radiative flux at the surface decreased by 6 to $15 \mathrm{~W} / \mathrm{m}^{2}$ and at the top of the atmosphere (TOA) decreased by 3 and $9 \mathrm{~W} / \mathrm{m}^{2}$, with strongest values located over the areas of largest emissions (Fig. 1c, d). (Unfortunately, observational estimates of long-term radiative flux changes are unavailable and a comparison of these simulated changes with observations is not straight forward. One would have to rely on shorter periods and simulations with fixed SSTs to reduce the effects of internal variability).

Increases in anthropogenic aerosol emissions have played a dominant role in driving a shift to an earlier monsoon onset and a weakening of the seasonal rainfall since the 1950s (Ramanathan et al. 2005; Lau and Kim 2010; Bollasina et al. 2011, 2014; Turner and Annamalai 2012; Salzmann et al. 2014; Li et al. 2015, 2016; Krishnan et al. 2016; Guo et al. 2016). Aerosols from both local (i.e., within South Asia) and remote sources are important in shaping historical changes in seasonal rainfall, although their relative contributions are still uncertain (Bollasina et al. 2014; Guo et al. 2016). Recent observational evidence also suggests that natural and anthropogenic aerosols, can affect daily-scale rainfall events over South Asia, including dry spells (Vinoj et al. 2014; Dave et al. 2017). The relative influence of local and remote aerosols on historical changes in daily-scale rainfall events in the presence of other external climate forcings is yet to be examined.

We therefore seek to better understand the influence of aerosols on mean and daily-scale rainfall characteristics (wet events, dry events, and rainless day frequency) over South Asia by addressing three main questions: (1) Do anthropogenic aerosols have a stronger influence than other external forcings on the spatial pattern of changes in daily rainfall characteristics during the peak monsoon season? (2) Is the overall aerosol response most strongly associated with direct radiative effects or aerosol-cloud interactions ("indirect effects")? (3) How are these rainfall changes influenced by aerosol emissions from local and remote regions?

Our analysis primarily employs an ensemble of simulations conducted with the NOAA Geophysical Fluid Dynamics Laboratory CM3 (GFDL-CM3) coupled climate model. GFDL-CM3 has been previously used to identify key influences of anthropogenic aerosols in driving the overall weakening trend of the summer monsoon and its earlier onset during the second half of the twentieth century (Bollasina et al. 2011, 2013), which have subsequently been supported by analysis of multi-model ensembles ( $\mathrm{Li}$ et al. 2015; Salzmann et al. 2014; Guo et al. 2015). In this study, we employ a set of GFDL-CM3 single-forcing experiments to test the influence of anthropogenic aerosols on daily-scale precipitation characteristics relative to GHGs and natural forcings. In addition, we use targeted experiments to understand the mechanisms by which aerosols influence these characteristics over South Asia (including the role of direct and indirect effects), and isolate the contribution of local aerosols from that of non-South Asian aerosols. To evaluate inter-model differences in the influence of forcings on historical changes, we also compare results from the GFDL-CM3 model with a subset of models from the Coupled Model Intercomparison Project (CMIP5) suite (Taylor et al. 2012).

\section{Data and methods}

\subsection{Observations}

We analyze two widely-used gridded rainfall datasets derived from rain-gauge observations: the India Meteorological Department ("IMD") dataset, which contains gridded data at $1^{\circ} \times 1^{\circ}$ horizontal resolution from 1951 to 2013 (Rajeevan et al. 2010), and the Asian Rainfall HighlyResolved Observational Data Integration Towards Evaluation of Water Resources (“APHRODITE") dataset, which contains gridded data at $0.25^{\circ} \times 0.25^{\circ}$ horizontal resolution from 1951 to 2007 (Yatagai et al. 2012). These are the only available gridded, long-term, daily rainfall datasets for the region. While the IMD dataset is restricted to India, APHRODITE covers the entire Asian domain (Fig. S1). Longterm changes in rainfall characteristics over sub-regions of India show considerable differences between these datasets (Fig. S2).

\subsection{Climate model experiments}

We use a suite of ensemble experiments with the NOAA Geophysical Fluid Dynamics Laboratory (GFDL-CM3) global coupled chemistry-climate model with a $2^{\circ} \times 2.5^{\circ}$ horizontal resolution. This is one of the few global climate models to realistically simulate the observed climatological mean and daily characteristics of peak-monsoon season rainfall (Fig. S1; Sperber et al. 2013; Ashfaq et al. 2017). GFDL-CM3 simulates the observed climatological timing and spatial patterns of several summer monsoon seasonal rainfall characteristics with lower biases than most other CMIP5 models (Fig. S3; Ashfaq et al. 2017). The model also reasonably represents the overall observed pattern of 
changes in monsoon season rainfall characteristics though the finer-resolution observations have greater spatial heterogeneity (Fig. S2). GFDL-CM3 is also one of the few models to archive multi-member simulations of daily-scale climate under individual external forcings, which are needed to account for "internal" variability in decadal-scale changes (Salzmann and Cherian 2015).

The GFDL-CM3 simulations use the standard CMIP5 historical anthropogenic emissions (Lamarque et al. 2010). In addition to the direct radiative effects of aerosols, the model includes a physically-based representation of aerosol-cloud interactions (commonly referred to as the aerosol "indirect effects") (Donner et al. 2011; Levy et al. 2013). Aerosol indirect effects are simulated for liquid clouds and are parameterized for stratiform cloud microphysics (Ming et al. 2007; Golaz et al. 2011; Levy et al. 2013). In GFDL-CM3, water soluble aerosols (i.e. sulfate, sea-salt and organic carbon) act as cloud condensation nuclei (CCN) following the parameterizations of Ming et al. (2006) and (2007). Black carbon is assumed to be insoluble. Anthropogenic sulfate aerosols, which are more efficient $\mathrm{CCN}$ than the other aerosol species, are the major driver of changes in $\mathrm{CCN}$ and, therefore, of aerosol indirect effects in the model (Levy et al. 2013). Further, aerosols are considered as prognostic variables, and sulfate and black carbon are internally mixed using a uniform mixing scheme for radiative transfer calculations (Persad et al. 2017). These aerosol species are, however, assumed to be externally mixed for the estimation of aerosol indirect effects in the stratiform cloud microphysics scheme (Salzmann et al. 2010). Dust concentrations show negligible changes during the twentieth century as GFDLCM3 dust emission changes are modulated only by modest variations in the wind speed (i.e., the model does not simulate dust emission changes associated with land use/ land cover change) (Pu and Ginoux 2016). One limitation of the representation of aerosols that has implications for this study is that aerosols in GFDL-CM3 do not interact with deep convection (Donner et al. 2011), which is also a limitation of most other global climate models (Rotstayn et al. 2014). More information on the GFDL-CM3 model formulation can be found in Donner et al. (2011).

In this study, we use three sets of GFDL-CM3 ensemble experiments. The first set of simulations includes experiments that are part of the public CMIP5 archive. This set consists of a 5-member ensemble with all historical forcings ("ALL-Forcing"), and three 3-member individualforcing ensembles forced by changes in greenhouse gases ("GHG-Only"), anthropogenic aerosols ("Aerosol-Only"), and solar and volcanic activity ("Natural-Only") in isolation. The individual members within each respective ensemble differ only in their initial conditions and, therefore, the spread between them results from internal variability in the presence of the forcing. An additional 600-year preindustrial control simulation ("PIcontrol") with forcings fixed at preindustrial levels is used to quantify the range of unforced internal variability. This suite of experiments allows us to study the relative influence of individual forcings on simulated historical changes, while simultaneously considering internal variability and removing model differences that may confound interpretation in a multi-model framework (e.g., differences in model resolutions, parameterizations, and aerosol representations).

The second set of simulations includes an additional 3 -member ensemble in which aerosols interact only with clouds but not with radiation (i.e., the aerosol direct effect is switched off; Levy et al. 2013). This ensemble is designed to isolate the role of aerosol indirect effects in driving the overall changes in the Aerosol-Only ensemble.

The third set of simulations includes two complementary 3-member ensembles, designed to examine the relative influence of local and remote aerosols. The first has varying aerosol emissions over South Asia and constant preindustrial levels over all other regions (South Asian Aerosol Emissions). The second has varying aerosol emissions over all remote regions and constant preindustrial levels over South Asia (Remote Aerosol Emissions). In both cases, other external forcing factors are kept constant at preindustrial levels.

Given the GFDL-CM3 model's overall performance, the availability of multiple realizations of single-forcing experiments, and the availability of experiments that isolated the direct and indirect effects and the roles of local and remote aerosols, we determine that GFDL-CM3 is a unique tool for exploring the influence of aerosols on historical changes in the South Asian monsoon rainfall characteristics.

However, there are substantial uncertainties associated with the representation of aerosols and aerosol-cloud interactions in the current generation of climate models (Boucher et al. 2013; Rotstayn et al. 2015), and GFDL-CM3 is known to have an overly-strong aerosol effect (Levy et al. 2013). Therefore, we complement our analysis with three other CMIP5 models (Table 1). These models are selected based on the availability of multiple realizations with individual forcings (e.g., aerosols and GHGs) at a daily resolution. They have varying degrees of biases in representing the climatology, and changes in surface radiative forcing and precipitation over the Indian subcontinent. Figure S3 compares the simulated rainfall mean and variability in these models with the CMIP5 suite and their representation of historical trends in several rainfall characteristics. Among the 4 models analyzed in this study, GFDL-CM3 and CCSM4 have relatively low biases in representing the monsoon precipitation and circulation characteristics, while CSIRO-MK3.6.0 and CanESM2 have larger biases (Fig. S3; Ashfaq et al. 2017).

Critically for our analysis, the four models have varying aerosol effective radiative forcings (Rotstayn et al. 2015) and representations of aerosol effects (Salzmann et al. 2014) 
Table 1 Details of climate model experiments used in the study, partly based on Salzmann et al. (2014) and Ekman (2014)

\begin{tabular}{lcll}
\hline Model & $\begin{array}{l}\text { Ensemble members (all-forc- } \\
\text { ing, individual-forcing) }\end{array}$ & Aerosol effects & References \\
\hline GFDL-CM3 & 5.3 & Direct and indirect effects (cloud-albedo and cloud-lifetime) & Donner et al. (2011) \\
CSIRO-MK3.6.0 & 10.10 & Direct and indirect effects (cloud-albedo and cloud-lifetime) & Rotstayn et al. (2012) \\
CCSM4 & 3.3 & Direct effects only & Gent et al. (2011) \\
CanESM2 & 5.5 & Direct effects and indirect effects (cloud-albedo only) & Ma et al. (2010), \\
& & & Arora et al. (2011) \\
\hline
\end{tabular}

(Table 1). GFDL-CM3 and CSIRO-MK3.6.0 are amongst the few CMIP5 models that include aerosol indirect effects, whereas CanESM2 only includes one indirect effect (cloudalbedo) and CCSM4 does not include either (Salzmann et al. 2014). Further, GFDL-CM3 has the strongest aerosol effective radiative forcing (ERF) of all CMIP5 models, followed by CSIRO-MK3.6.0 within our subset of models (Rotstayn et al. 2015). The aerosol ERFs of both GFDLCM3 $\left(-1.6 \mathrm{~W} / \mathrm{m}^{2}\right)$ and CSIRO-MK3.6.0 $\left(-1.4 \mathrm{~W} / \mathrm{m}^{2}\right)$ are higher than the ERF estimates $\left(-0.45\right.$ to $\left.-0.93 \mathrm{~W} / \mathrm{m}^{2}\right)$ derived from satellite observations (Boucher et al. 2013). Aerosol indirect effects are a major contributor to the aerosol ERF, and are particularly sensitive to the model's cloud tuning parameters, as demonstrated by Golaz et al. (2011) and (2013) specifically for GFDL-CM3 (but also true for other models). These pervasive uncertainties in aerosols and their interactions with clouds have important implications for our understanding of the influence of aerosols on climate processes, including precipitation. Although we are able to conduct an initial quantification of the influence of these uncertainties on our results, that quantification is limited by the number of models that both incorporate such effects and have multiple realizations of individual-forcing simulations.

\subsection{Characteristics of the daily rainfall distribution}

We focus our analysis on rainfall characteristics during the peak-monsoon (July-August) months for three main reasons. First, at this time, the monsoon is fully established over the Indian Subcontinent. Second, monsoonal rainfall and the occurrence of wet/dry events are highest during July-August (Pai et al. 2015; Rajeevan et al. 2010). Third, the peak months coincide with the growth period of the Kharif ("monsoon") crops, meaning that identifying the drivers of monsoon changes during these months has direct implications for agriculture.

We analyze four metrics of the peak-season daily rainfall distribution: mean rainfall, frequency of rainless days, frequency of deficit rainfall events (dry events), and frequency of excess rainfall events (wet events). Following Salinger and Griffiths (2001), we define rainless days as days with rainfall $<1 \mathrm{~mm} /$ day. In accordance with previous studies
(Annamalai and Slingo 2001; Mandke et al. 2007; Rajeevan et al. 2010; Singh et al. 2014), we define wet and dry events based on daily rainfall anomalies exceeding a certain standardized threshold. Standardized rainfall anomalies are calculated based on the mean and standard deviation calculated for the baseline period (1951-1975). Protracted anomalies with consecutive days meeting this criterion are considered a single event. We use a threshold of \pm 0.68 standard deviations $(\sigma)$, which approximates the $25 \mathrm{th} / 75$ th percentile of a normal distribution. The wet event frequency is defined as the number of events with daily rainfall anomalies exceeding the $+0.68 \sigma$ threshold in a season, while the dry event frequency is the number of events with daily rainfall anomalies exceeding the $-0.68 \sigma$ threshold.

\subsection{Statistical analysis}

We examine long-term changes in these characteristics during the 1951-2000 period, when the South Asian monsoon rainfall underwent a noticeable linear decrease of $\sim 10 \%$ (e.g., Bollasina et al. 2011; Turner and Annamalai 2012; Singh et al. 2014). This weakening occurred simultaneously with an increase in regional anthropogenic aerosol emissions, particularly of sulfates and black carbon, which increased by $\sim 6$ times since the early twentieth century (e.g., Ramanathan et al. 2001, 2005; Lau and Kim 2010), and a change in phase of the Pacific Decadal Oscillation (PDO) a mode of multidecadal internal variability - from negative to positive (Salzmann and Cherian 2015). Note, however, that even if the processes driving such internal modes of variability are accurately simulated, the exact timing of particular historical transitions should not be expected to be reproduced in individual coupled climate model realizations. This period also aligns with the availability of the historical forcing simulations (which, according to the CMIP5 protocols, run through 2005).

We compute differences in rainfall characteristics between two 25-year periods (1951-1975) and (1976-2000), which equally divide this 50-year period. We use a non-parametric permutation test to quantify the significance of changes in the mean of the distribution of different rainfall characteristics between the two periods, at each grid point (Stanberry 
2013). The permutation test involves calculating changes between these 25 -year periods by randomly reorganizing the original timeseries several times. The p-value of this test is the proportion of absolute changes from these resampled timeseries that exceed the absolute magnitude of change between these time periods in the original time series. This significance test makes no assumptions about the underlying distribution, thereby accommodating the non-normality of the distributions of the various rainfall characteristics. To account for internal variability in the model ensembles, we first calculate changes for each ensemble member, and then average the changes across the ensemble to calculate the "forced response" to each forcing factor. The robustness of the model results at each grid point is measured by the agreement on the direction and statistical significance of the changes across the individual ensemble members.

\subsection{Approach for identifying spatial similarity}

To provide a quantitative estimate of the relative influence of individual forcing factors in driving South Asian monsoon rainfall changes, we use the pairwise Pearson's correlation method to assess the similarity between the spatial pattern of changes in the ALL-Forcing ensemble and those in each individual-forcing ensembles. Given the spatial inhomogeneity of the aerosol distribution, we calculate the pattern correlations for the region $6^{\circ}-32^{\circ} \mathrm{N}, 68^{\circ}-90^{\circ} \mathrm{E}$ (shown in Fig. 1c), which encompasses the area of strong increase in aerosol emissions and forcing (Fig. 1a-d). Additionally, this domain accounts for the competition between rainfall changes over land and nearby ocean, which ultimately represent two facets of the response of the overall coupled monsoon system. The pattern correlations are calculated between each ensemble member of the ALL-Forcing experiment (5 realizations) and each ensemble member of each individualforcing experiment (3 realizations for each forcing), yielding 15 correlation values for each pair of forcing experiments. We also report the spatial correlations between the ensemble-mean changes in the different forcing experiments.

\subsection{Quantifying the role of internal variability relative to "forced" changes}

Changes in rainfall characteristics could result from internal fluctuations of the climate system that are largely independent of any forced changes (i.e., "internal variability"). To quantify the range of changes that could arise from internal variability, we calculate the distribution of changes between all pairs of non-overlapping 25-year periods in the unforced 600-year GFDL-CM3 PIcontrol simulation. Next, we calculate the distribution of spatial correlations between the changes calculated in the PI simulation and those calculated from the five members of the ALL-Forcing ensemble
("ALL-PI distribution"). Then, we calculate the distribution of spatial correlations between the changes calculated in the five members of the ALL-Forcing ensemble and the three individual ensemble members for each single-forcing experiment (respectively). Finally, we use the Kolmogorov-Smirnov ("K-S") test to quantify the significance of the difference between the ALL-PI distribution of correlations and the respective ALL-Forcing/single-forcing distributions of correlations. The p-value from the $\mathrm{K}-\mathrm{S}$ test indicates the confidence with which we can reject the null hypothesis that the ALL-Forcing changes arose from internal variability alone. Rejection of the null-hypothesis with high confidence implies that the forced changes are outside of the range expected from internal variability. In contrast, the inability to reject the null-hypothesis suggests that an influence of that individual forcing cannot be concluded.

\section{Results and discussions}

\subsection{Influence of individual forcings on daily rainfall characteristics}

For all four rainfall characteristics, the spatial pattern of changes in the ALL-Forcing ensemble mean shows the closest similarity to the Aerosol-Only ensemble, with the GHG-Only and Natural-Only ensembles exhibiting little correspondence (Fig. 2a). The spatial correlation between the ensemble mean ALL-Forcing and Aerosol-Only changes is weaker for mean rainfall $(0.4, \mathrm{p}$-value $<0.05)$ than for the daily rainfall characteristics, particularly for rainless day frequency $(0.7, \mathrm{p}$-value $<0.05)$ and dry event frequency $(0.6, \mathrm{p}$-value $<0.05)$. In contrast, the spatial correlations between the ALL-Forcing and GHG-Only changes are significantly negative for all characteristics, suggesting a consistent opposing effect of aerosols and GHGs. Changes in the Natural-Only ensemble are uncorrelated with changes in the ALL-Forcing ensemble for all metrics, with the exception of a significantly negative correlation for rainless day frequency. These results are robust across the various ensemble members (Fig. 2b-e), though in the case of wet event frequency, the individual members have considerably lower spatial correlations than the ensemble means, likely due to dampening of the internal variability.

Observations exhibit robust declines in mean peak-season rainfall over eastern-central India, and moderate increases over parts of western and northwestern India between the 1951-1975 and 1976-2000 (Fig. S2a-b). Changes in mean peak-season rainfall in the ALL-Forcing ensemble display a coherent large-scale east-west dipole pattern across South Asia, largely similar to the observed pattern of changes, albeit of slightly weaker magnitude and with sub-regional biases (e.g., over the Western Ghats) (Fig. 3b). Mean rainfall 
a

Spatial Correlations between Ensemble-mean Changes in All-Forcing and Individual Forcing Experiments
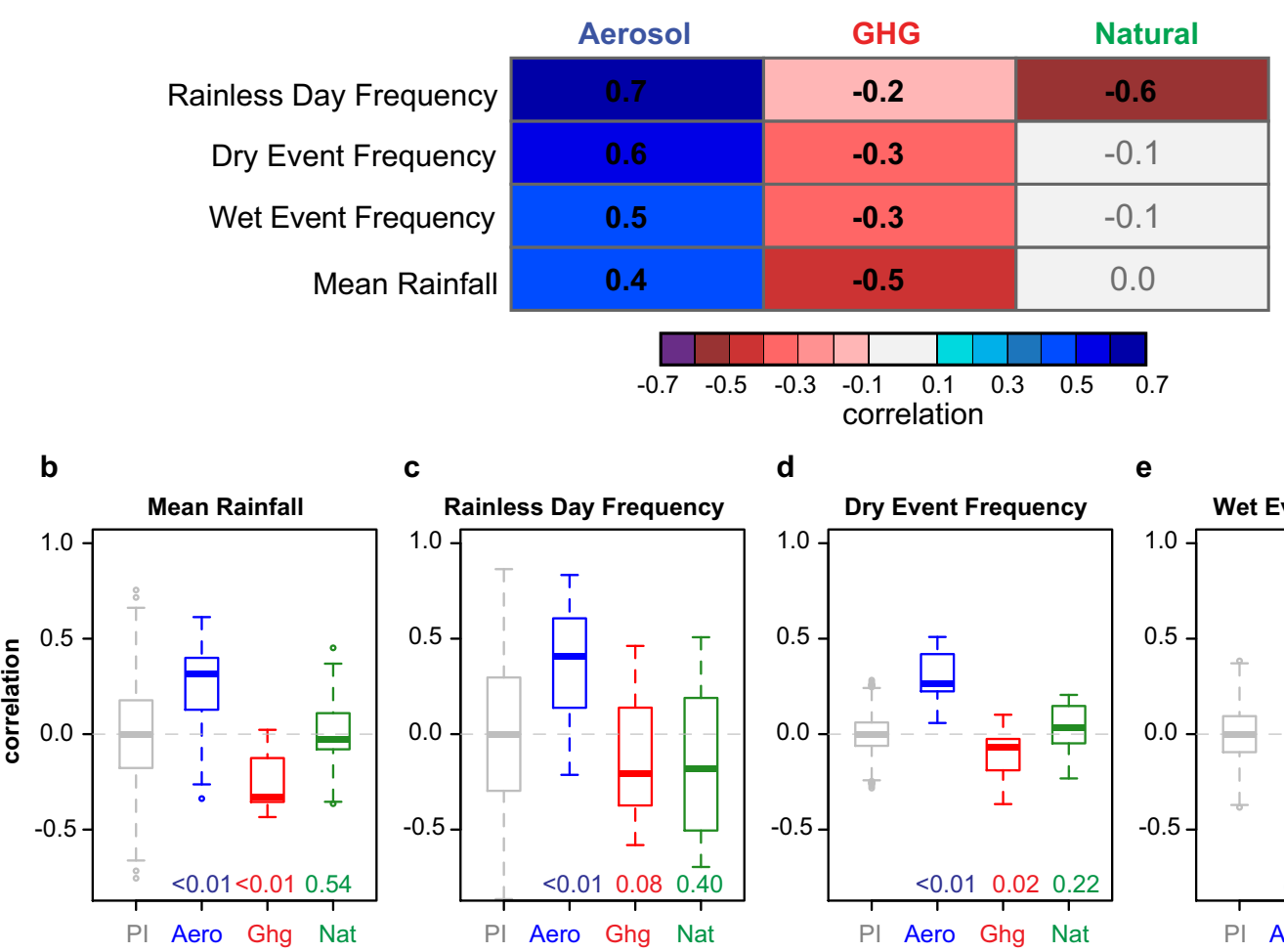

C

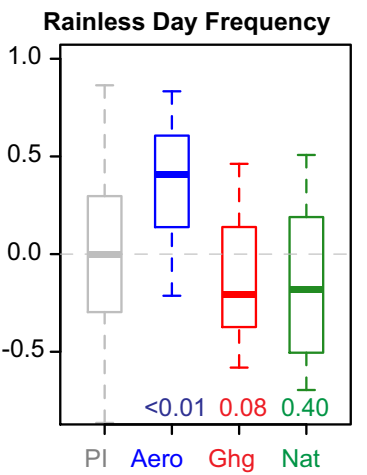

d

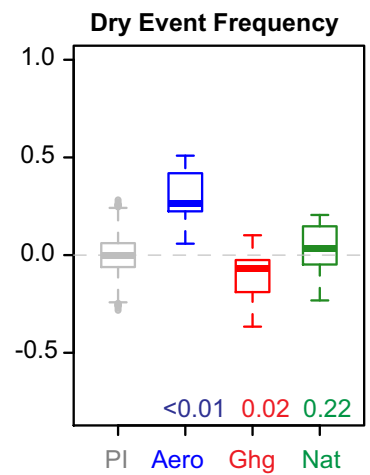

e

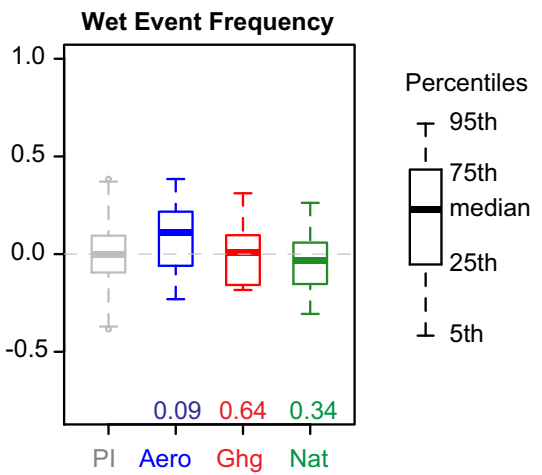

Fig. 2 Influence of internal variability and individual forcings on ALL-forcing changes: a spatial correlations between ensemble mean changes in the ALL-Forcing and individual forcing experiments. b-e Range of spatial correlations between changes in all ensemble members of the ALL-Forcing simulations with all ensemble members of the preindustrial (PI; grey), Aerosol-Only (Aero; blue), GHG-Only
(GHG; red), and Natural-Only (Nat; green) simulations, over South Asia (box in Fig. 1c). Numbers below each boxplot are the p-values for the Kolmogorov Smirnov test between the distribution of spatial correlations of ALL-Forcing with PIcontrol changes and ALL-Forcing with individual forcing changes. In the text, we refer to all p-values below 0.05 as statistically significant in GFDL-CM3 decreases significantly by $\sim 0.4-0.8 \mathrm{~mm} /$ day over eastern-central India, the climatologically wetter sub-region of South Asia, but increases significantly by $\sim 0.3-0.5 \mathrm{~mm} /$ day over northwestern India and Pakistan, the climatologically drier sub-region of South Asia (Fig. 3a, b). A very similar pattern, though of larger magnitude, is recognizable in the Aerosol-Only ensemble (Fig. 3c). In contrast, changes induced by GHGs are largely opposite to those induced by aerosol forcing, including a wetting of eastern-central India and a drying to the west (Fig. 3d). In the Natural-Only ensemble, rainfall is suppressed over the entire domain (Fig. 3e). This indicates that the overall ALLForcing response of mean peak-season rainfall in the GFDLCM3 model is largely driven by aerosol forcing.

The simulated climatology of rainless day frequency (days with $<1 \mathrm{~mm} /$ day) during the peak-monsoon season features the highest occurrence over northwestern India, Pakistan, and parts of peninsular India, and fewer than 6 days over the rest of the domain (Fig. 3f). Changes in rainless day frequency have considerable uncertainties in observations, with widespread increases in the IMD dataset and spatially variable and contrasting trends in the APRHODITE dataset (Fig. S2d-e). The pattern of changes in rainless day frequency in the GFDL-CM3 ALL-Forcing ensemble is more consistent with the declines over northwestern India and slight increases over eastern-central India in the APHRODITE dataset (Fig. S2e-f). The simulated pattern of changes in rainless day frequency closely resembles the corresponding changes in mean rainfall (Fig. 3b, g). The most robust anomalies in rainless days occur over the climatologically dry northwestern sub-region, where both the ALL-Forcing and Aerosol-Only ensembles simulate decreases of up to 3-4 days (Fig. 3g-h). In contrast, there are relatively small and largely insignificant changes in the frequency of rainless days over eastern-central India in both the ALL-Forcing and Aerosol-Only ensembles (Fig. 3g, h). The GHG-Only and Natural-Only ensembles show an overall weak increase in rainless day frequency across much of the domain, with the only significant changes being increases over parts of the western sub-domain in the GHG-Only ensemble (Fig. 3i, j). 

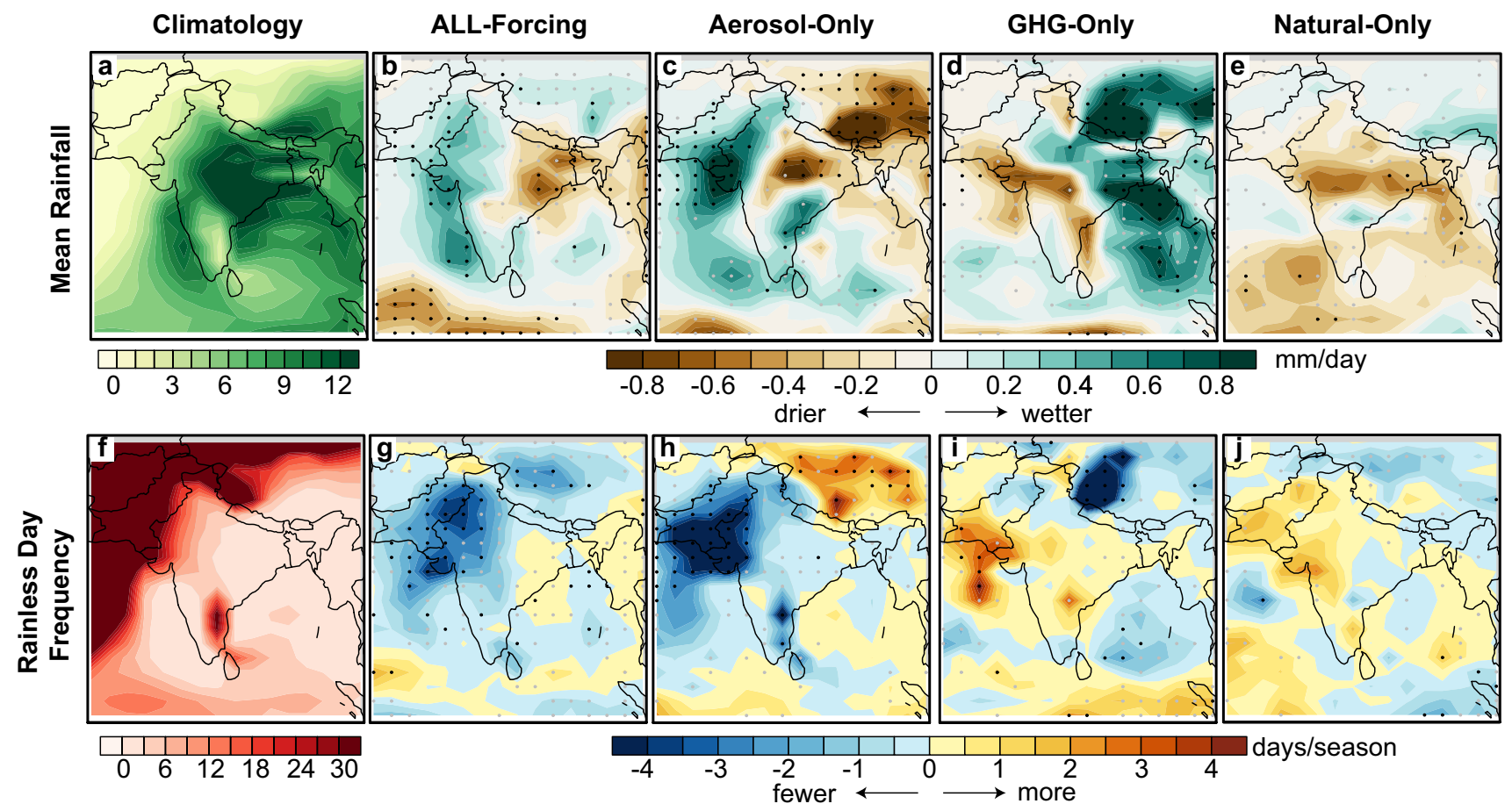

- All ensemble member changes in the same direction and at least one is significant - All ensemble member changes are in the same direction

Fig. 3 Peak-season rainfall characteristics: climatological mean (1951-1975) and ensemble mean changes (1976-2000 relative to 1951-1975) in a-e mean rainfall and $\mathbf{f}-\mathbf{j}$ frequency of rainless days (precipitation $<1 \mathrm{~mm} /$ day) during the peak-season (July-August) in the ALL-Forcing, Aerosol-Only, GHG-Only, and Natural-Only

Together, these results suggest that the simulated increases in mean rainfall over the northwestern sector of the domain in the ALL-Forcing and Aerosol-Only ensembles (Fig. 3b) are driven at least in part by aerosol-induced increases in the number of days with rainfall (converse of rainless day frequency), while the strong declines in mean rainfall over central India in the ALL-Forcing and Aerosol-Only ensembles (Fig. 3b, c) are driven primarily by decreases in the intensity of rainfall (average precipitation on rainy days) rather than decreases in the number of days with rainfall (Fig. S2i). This decline in rainfall intensity over much of central India simulated in the ALL-Forcing ensemble is consistent with IMD and APHRODITE, though there are slight differences in the location of peak changes (Fig. S2g-h).

The highest climatological frequency of wet and dry events generally occurs over the areas that experience the heaviest mean climatological rainfall (Fig. 4a, f). Easterncentral India typically averages $\sim 5-7$ wet events and $\sim 6-8$ dry events during the peak-monsoon season in GFDL-CM3 (Fig. 4a, f). Observed changes in wet and dry event frequency in the two observational datasets are broadly consistent. However, there are discrepancies in the magnitude simulations. Grey dots in panels indicate that all ensemble members agree on the direction of change. Black dots indicate that all ensemble members agree on the direction of change and the change in at least one member is significant at the $5 \%$ level

and spatial pattern of changes, again emphasizing the observational uncertainties in these measures of rainfall extremes (Fig. S2i-o). The ALL-Forcing ensemble broadly simulates the observed patterns of reduced wet event frequency in eastern central India and increased dry event frequency in the same region, albeit with less heterogeneity. Wet event frequency significantly decreases by over 0.6 events/season-and dry event frequency significantly increases by over 0.8 events/season-over eastern-central India during the 1976-2000 period relative to the 1951-1975 period in GFDL-CM3 (Fig. 4b, g). In addition, the ALL-Forcing ensemble shows significant increases in wet event frequency of approximately the same magnitude over the climatologically drier regions of Pakistan and northwestern India (Fig. 4g). Among the single-forcing ensembles, this ALL-Forcing dipole pattern of changes in dry and wet event frequency is only present in the Aerosol-Only ensemble (Fig. 4). In contrast, the GHG-Only ensemble exhibits changes that are largely opposite to the Aerosol-Only changes, with wet event frequency increasing significantly across northern and eastern India and decreasing significantly over peninsular India (Fig. 4d, i). The Natural-Only ensemble shows decreases in wet event frequency and 

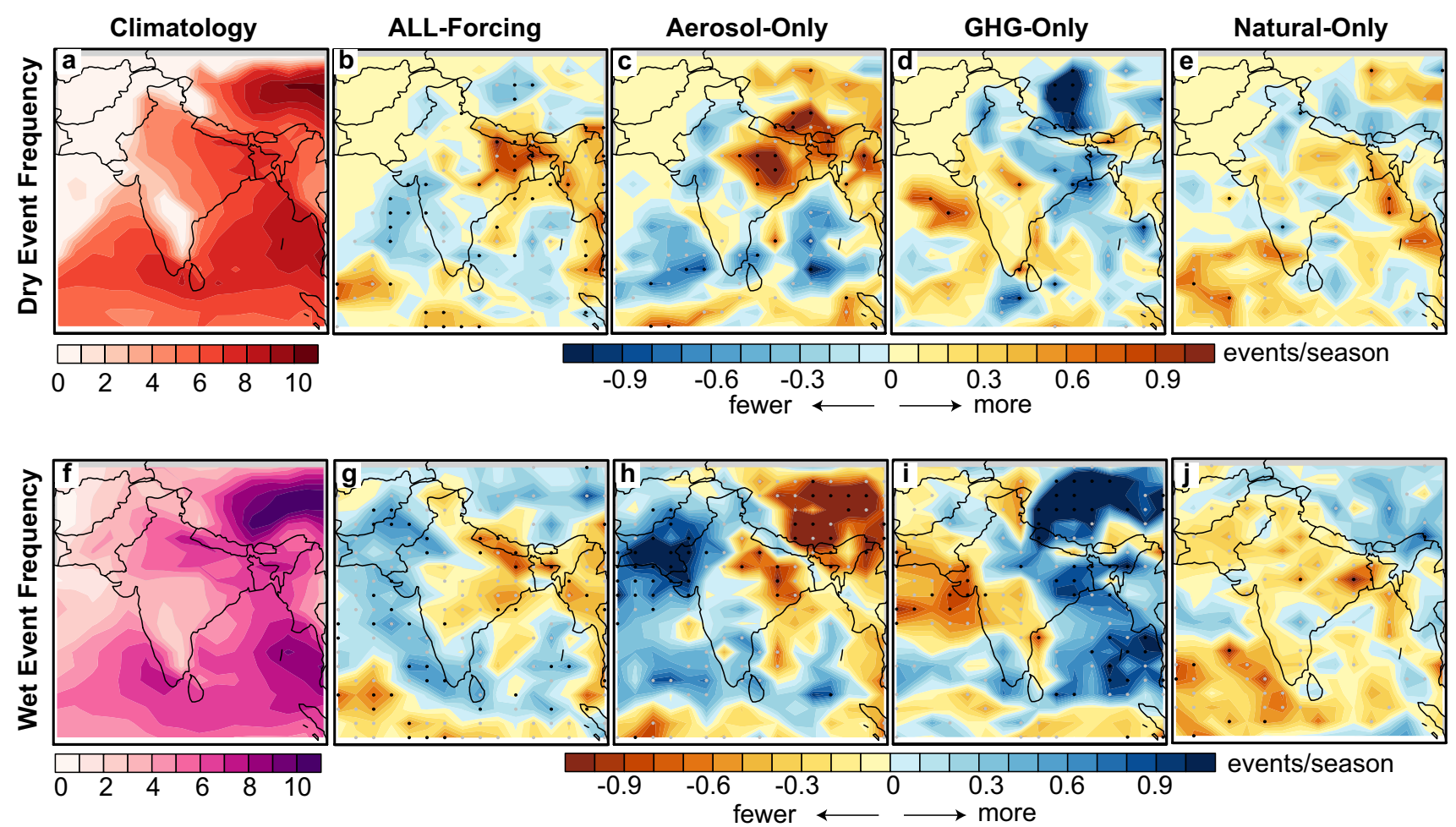

- All ensemble member changes in the same direction and at least one is significant - All ensemble member changes are in the same direction

Fig. 4 Dry and wet event characteristics: as in Fig. 3, but for $\mathbf{a}-\mathbf{e}$ dry event frequency, and $\mathbf{f}-\mathbf{j}$ wet event frequency. Here, dry and wet events refer to individual or multiple consecutive day events with rainfall anomalies exceeding $\pm 0.68 \sigma$

increases in dry event frequency across most of the domain, but the changes are of smaller magnitude and less significance, and bear little similarity to those in the ALL-Forcing ensemble. Along with the decline in mean and increase in rainless day frequency, these changes in wet and dry event frequency in the Natural-Only ensemble are consistent with the presence of an active volcanic eruption period, which has an overall weakening effect on the monsoon (Ning et al. 2017).

The similarity of the magnitude and spatial pattern of historical changes in mean rainfall, rainless day frequency, and wet/dry event frequency between the ALL-Forcing and Aerosol-Only ensembles (Figs. 2, 3, 4) indicates a strong and robust aerosol imprint on the characteristics of daily rainfall over South Asia in the GFDL-CM3 model. To determine whether the forced changes are statistically distinguishable from those associated with internal climate variability, we compare the spatial correlations between the ALL-Forcing and single-forcing ensembles with the spatial correlations between the ALL-Forcing ensemble and the PIcontrol simulation (see Sect. 2.6) (changes in the 600-year PIcontrol simulation are calculated for all pairs of non-overlapping 25 -year periods). For all characteristics (Fig. 2b-e), the ALL-PI correlations are small (25th-75th percentile of the correlation distribution $< \pm 0.2$ ) and centered around zero, suggesting a relatively minor role of internal variability in generating the ALL-Forcing patterns of changes. For the rainfall characteristics that exhibit the strongest influence of aerosol forcings (mean rainfall, rainless day frequency, and dry event frequency), the distribution of correlations between the ALL-Forcing and Aerosol-Only patterns are significantly different ( $\mathrm{p}$-value $<0.01)$ from the patterns arising from unforced variability. A similar result, although slightly less significant, holds for changes in wet event frequency ( $p$-value $=0.09$ ). For all characteristics, correlations between the ALL-Forcing and Natural-Only ensembles are statistically indistinguishable from correlations between the ALL-Forcing ensemble and the PIcontrol simulation, suggesting that the Natural-Only changes are within the range of internal climate variability.

Together, these results provide strong evidence for the predominant role of anthropogenic aerosols in driving the ALL-Forcing pattern of changes in multiple daily rainfall characteristics in the GFDL-CM3 model. In addition, they highlight the greater similarity between the ALL-Forcing and Aerosol-Only pattern of changes for rainless day frequency and dry event frequency than for the seasonal mean, 
indicating that aerosols likely have a larger influence on lowto moderate-intensity rainfall events.

\subsection{The role of aerosol-cloud interactions}

To understand the mechanisms by which aerosols influence daily rainfall characteristics, we separate the contribution of aerosol-cloud interactions (i.e. indirect effects) from the overall aerosol effect simulated in the Aerosol-Only ensemble. To do so, we make use of an additional 3-member ensemble experiment (Aerosol Indirect-Only) in which aerosols do not interact with radiation (i.e., the aerosol direct effect is not active; see Sect. 2.2), allowing us to isolate the role of aerosol indirect effects (Fig. 5). The similarity in the spatial pattern and magnitude of mean rainfall changes between the Aerosol-Only and the Aerosol Indirect-Only ensembles (Fig. 5a) — in particular the dipole pattern of drying over eastern-central India and the wetting over southern India and the western regions-suggests that aerosol indirect effects play a predominant role in shaping the response of peak-monsoon rainfall to aerosol forcing. Similarly, the correspondence between changes in net radiation at the top of the atmosphere in both ensembles also confirm the predominant role of aerosol indirect effects in driving the overall Aerosol-Only changes, whilst not precluding a secondary role of aerosol direct effects (Fig. S4). These aerosol indirect effects are largely associated with changes in anthropogenic sulfate concentrations as black carbon are not treated as $\mathrm{CCN}$ in the model. The stronger and more expansive rainfall suppression seen in the Aerosol Indirect-Only ensemble compared with the Aerosol-Only ensemble indicates that aerosol direct effects partly offset the changes induced by the aerosol indirect effects.

In addition, aerosol indirect effects appear to be important for the aerosol-forced changes in dry and wet event frequency (Fig. 5e-h). Both the Aerosol-Only and the Aerosol Indirect-Only ensembles display key similarities in the above patterns of change, including increased frequency of dry events and decreased frequency of wet events over eastern-central India, and changes of opposite sign but smaller magnitude over the rest of the domain (Fig. 5e-h). However, changes in the frequency of rainless days in these two ensembles are less similar (Fig. 5c, d). The Aerosol Indirect-Only ensemble largely shows increases in rainless day frequency (i.e. decrease in rainy days) over much of South Asia in contrast to the robust decreases simulated in the Aerosol-Only ensemble. While the robust increases in the Aerosol Indirect-Only ensemble occur mainly over eastern India, the decreases in rainless day frequency (i.e. increase in rainy days) in the Aerosol-Only ensemble are strongest and most significant over northwestern India and Pakistan. This dissimilarity indicates that indirect effects do not influence the overall Aerosol-Only change in occurrence
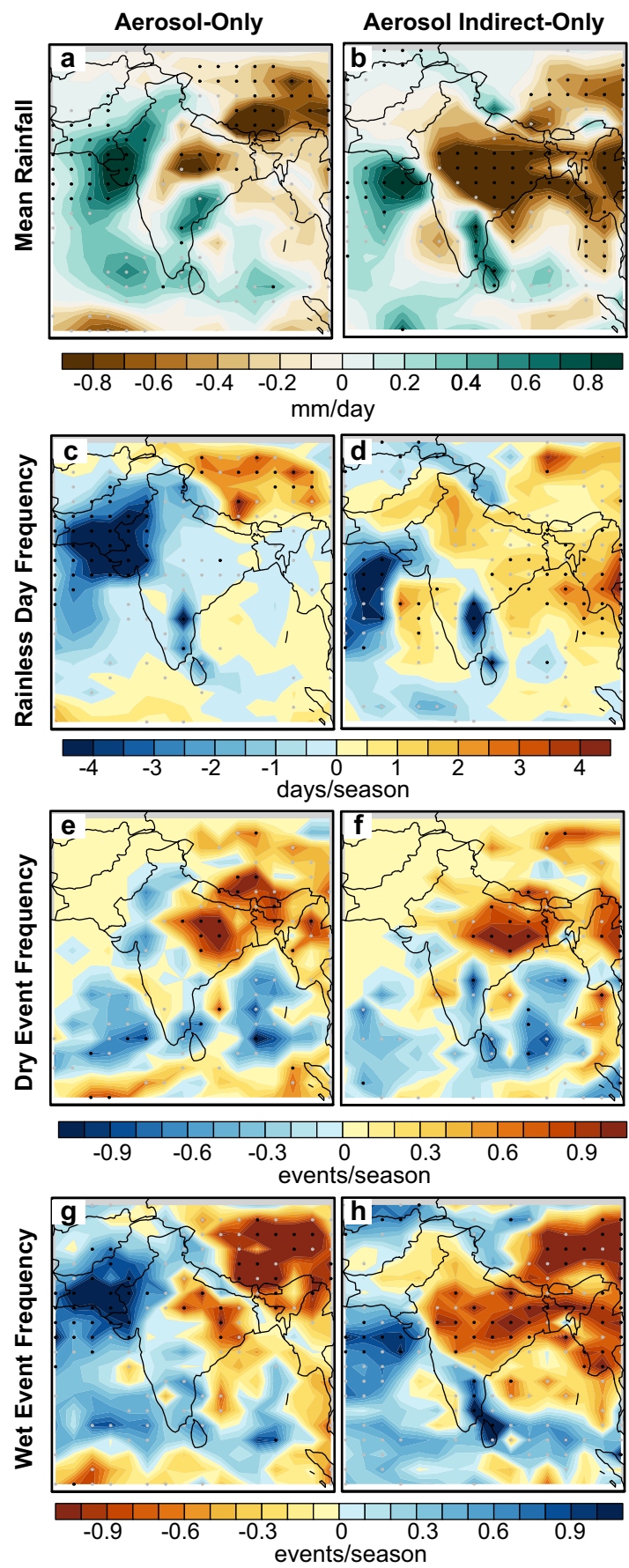

- All ensemble member changes in the same direction and at least one is significant - All ensemble member changes are in the same direction

Fig. 5 Role of aerosol indirect effects: ensemble mean changes (1976-2000 relative to 1951-1975) in July-August a-b mean rainfall, $\mathbf{c}-\mathbf{d}$ rainless day frequency, $\mathbf{e}-\mathbf{f}$ dry event frequency, and $\mathbf{g}-\mathbf{h}$ wet event frequency in the Aerosol-Only simulations and Aerosol Indirect-Only simulations 
of rainy days, but instead have a stronger influence on the intensity of rainfall events.

The potential for the aerosol indirect-effects to influence the frequency of wet and dry event is rooted in the aerosol modulation of cloud and rainfall processes. Some observations and cloud-resolving modeling studies support the idea that aerosols could invigorate convection, particularly in deep convective clouds, which could support the intensification of rainfall events (Rosenfeld et al. 2008; Fan et al. 2012, 2016; Koren et al. 2014 and references therein). However, such convection-aerosol interactions are not included in coarse-resolution models including GFDL-CM3 (Donner et al. 2011; Rotstayn et al. 2015). A contrasting hypothesis is that enhanced aerosol concentrations suppress rainfall by increasing the number of $\mathrm{CCN}$. Higher number of $\mathrm{CCN}$ lead to reduced cloud droplet size and smaller droplets are likely to reduce the efficiency of rainfall formation in the clouds to produce less heavy rain and, to a lesser extent, increase rainless day frequency (e.g., Ramanathan et al. 2001; Forster et al. 2007; Rosenfeld et al. 2008; Fan et al. 2012; Li et al. 2016). Consistent with the latter hypothesis, we find a decline in precipitation intensity across central India in the Aerosol Indirect-Only ensemble, inferred from the relatively large decreases in mean rainfall and small changes in rainless day frequency (Fig. 5b, d). This decline in overall precipitation intensity manifests as a decrease in the frequency of wet events and an increase in the frequency of dry events (Fig. 5f, h). The largest decreases in rainfall intensity and associated changes in wet and dry event frequency are located over eastern-central India, where aerosol loading underwent the strongest increase (Fig. 1b).

Aerosol-forced rainfall variations are also associated with large-scale dynamic and thermodynamic changes, which are very similar to those driven by aerosol indirect effects alone (Fig. 6). The strong surface cooling $(>1.5 \mathrm{~K})$ in the northwest of the domain, predominantly driven by aerosol indirect effects, is associated with a reduction of the meridional pressure gradient over the Indian Subcontinent and, correspondingly, with a weakening of the low-level circulation (Fig. 6a-c, $\mathrm{d}-\mathrm{f}$ ). The west-east dipole pattern in mean rainfall and in wet event frequency corresponds closely to changes in moisture availability, likely associated with these aerosol-driven circulation changes (Fig. 6d-f). In addition, the patterns of changes in wet and dry event frequency in the Aerosol-Only ensemble largely follow the patterns of changes in vertical stability ${ }^{1}$

\footnotetext{
1 Vertical stability is calculated by computing the vertical difference in equivalent potential temperature (EPT) between two layers close to the surface ( $925 \mathrm{hPa}$ minus $2 \mathrm{~m}$ ), calculated using the expression suggested in Bolton (1980). By definition, EPT accounts for both changes in temperature and humidity as the moist parcel of air ascends and its vapor condenses, releasing latent heat. Warmer lowlevel temperatures and higher low-level humidity tend to increase instability.
}

associated with temperature and moisture changes (Fig. 6g-i). Increases in dry event frequency and decreases in wet event frequency are accompanied by increased vertical stability over eastern-central India in both ensembles.

These results suggest an important role of aerosol-cloud interactions in driving the total aerosol response of wet and dry event frequency over parts of central and eastern India, the region with largest aerosol increases. Direct radiative effects-through interactions with the circulation-also appear to be important in shaping changes in daily and mean rainfall characteristics over northwestern India and Pakistan, where aerosol loading shows little change. Aerosol direct effects appear to have contrasting effects on temperature and precipitation over this part of the domain, given the enhanced rainfall and weaker cooling in the Aerosol-Only ensemble relative to the Aerosol Indirect-Only ensemble (Figs. 5a-b, 6b-c). Although the response of daily-scale rainfall characteristics to individual forcing factors can be explained in part by seasonal-mean changes in the largescale atmospheric environment, a wide range of processes acting across spatial and temporal scales affect the monsoon rainfall and its daily-scale characteristics (e.g., Hurley and Boos 2014; Krishnamurthy and Shukla 2008; Rajeevan et al. 2010). Further research is needed to improve current understanding of the multitude of processes and features (e.g., monsoon depressions) governing sub-seasonal-scale rainfall variability of the region, including their modulation by individual external forcing factors.

\subsection{Impact of aerosols from local and remote sources}

In addition to aerosols emitted from sources within the domain, rising aerosol emissions over other parts of the world, particularly East Asia (Fig. 1a), have the potential to modulate the circulation and rainfall over South Asia (Bollasina et al. 2014; Guo et al. 2016). Here, we examine the relative importance of South Asian aerosol emissions compared to aerosols over the rest of the world ("Remote Aerosol Emissions") in shaping the regional response of rainfall characteristics to aerosols (Fig. 7). Note that changes in non-South Asian aerosols are mostly due to East Asian aerosol emissions, as emissions over North America and Europe show only small changes between the two historical periods considered in this analysis [not shown; see Fig. 1 in Bollasina et al. (2014)]. It is also worth noting that, despite multiple aerosol tranport and removal processes, the largest AOD changes are closely located over areas with the largest variations in aerosol emissions.

In the simulations with aerosols varying only over South Asia ("South Asian Emissions"), there is widespread decline in rainfall across much of India, with the largest changes over northern and eastern India (Fig. 7a), which is also the 

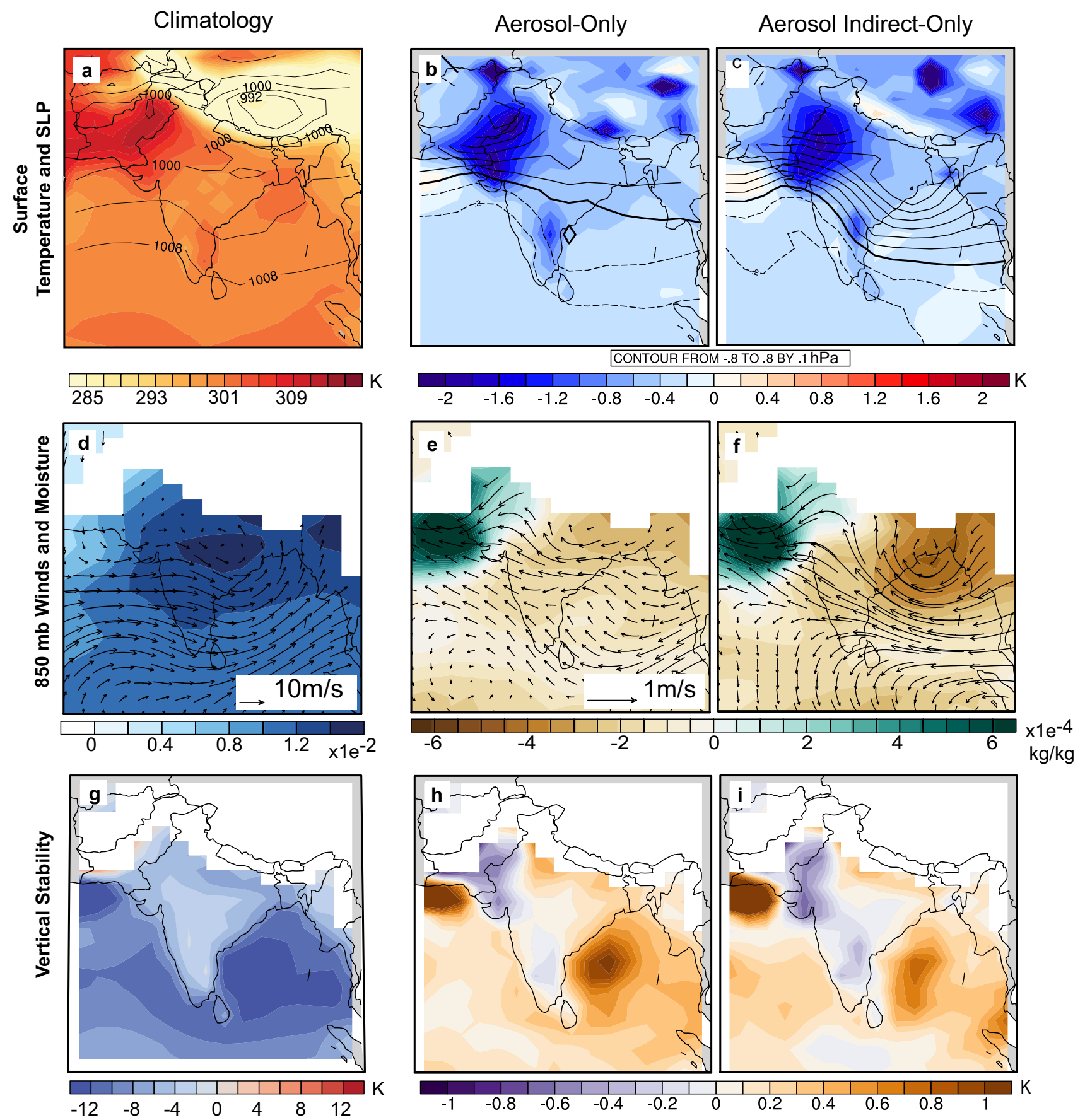

Fig. 6 Influence of indirect effects on thermodynamics and circulation: climatological mean (1951-1975) and ensemble mean changes (1976-2000 relative to 1951-1975) in the peak-season (July-August) a-c surface temperature (K, shading) and sea-level pressure (hPa, contours), d-f $850 \mathrm{mb}$ circulation and moisture (arrows represent

sub-region of largest forcing (Fig. 1b-d). This sub-region also experiences the strongest decreases in wet event frequency and increases in dry event frequency (Fig. $7 \mathrm{~g}, \mathrm{j}$ ), similar to the total aerosol response (Fig. 4c, h). In contrast, in the Remote Aerosol Emissions simulations, seasonal rainfall exhibits a winds and shading represents moisture), and $\mathbf{g}-\mathbf{i}$ vertical stability $(\mathrm{K}$; measured as the difference in equivalent potential temperature between $925 \mathrm{mb}$ and $2 \mathrm{~m}$ ) in the Aerosol-Only and Aerosol-Indirect Only simulations

north-south dipole pattern of changes with increases over the northern India and decreases over peninsular India (Fig. 7b). There are few robust and coherrent changes in the frequency of wet and dry events in these simulations that only include the remote aerosol emissions (Fig. 7h, k). However, rainless 
Fig. 7 Local and Remote Aerosols Impacts on Rainfall: ensemble mean changes (19762000 relative to $1951-1975$ ) in rainfall characteristics in (left column) simulations with anthropogenic aerosols increasing over South Asia and rest of the world emissions fixed at preindustrial levels ("South Asian Aerosol Emissions"), and (middle column) simulations with anthropogenic aerosols increasing over the rest of the world and aerosol emissions over South Asia fixed at preindustrial levels ("Remote Aerosol Emissions"). (Right column) Difference between the changes in the total aerosol experiment and the arithmetic sum of changes in the local and remote aerosol experiment, referred to as non-linear effects
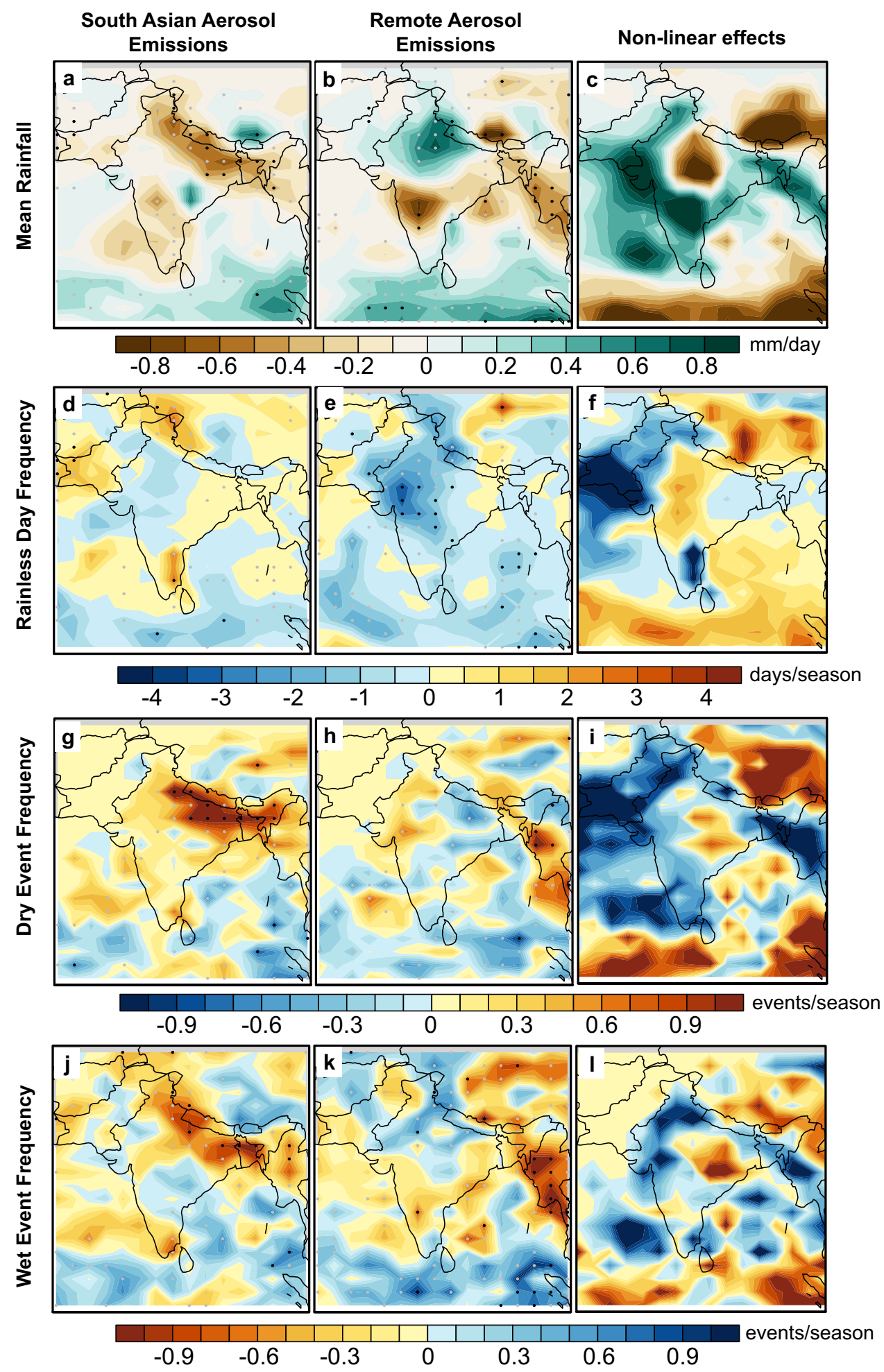

- All ensemble member changes in the same direction and at least one is significant - All ensemble member changes are in the same direction day frequency decreases over much of India, especially over the western half of the domain, closely resembling the total aerosol response (Fig. 3h, 7e). These results highlight the importance and distinct roles of aerosols from both sources in shaping the Aerosol-Only response in seasonal and daily rainfall characteristics. 
The non-linearity in the combined response to local and remote aerosols for these characteristics is notable, which likely results from feedbacks within the coupled climate system. To quantify the degree of nonlinearity between the climate impacts of emissions from local and remote sources, we calculate the difference between the ensemble-mean changes in the Aerosol-Only simulations and the arithmetic sum of changes in the South Asian and Remote Aerosol Emissions simulations (Fig. 7c, f, i, 1). For mean rainfall, the AerosolOnly changes (Fig. 3c) cannot be explained by the response to either South Asian or remote emissions, but closely resemble the pattern of nonlinear changes (Fig. $7 \mathrm{a}-\mathrm{c}$ ). While the response to remote aerosol emissions largely explains the Aerosol-Only changes in rainless day frequency over India (Fig. 3h), the overall changes over Pakistan resemble the nonlinear effects of combined remote and South Asian aerosols (Fig. 7d-f). For both the mean rainfall and rainless day frequency, the pattern of the nonlinear term suggests that the presence of local emissions acts to shift the region of wetting westward over northwestern India and Pakistan (Fig. 7c, f). In contrast, the Aerosol-Only changes in wet and dry event frequency over eastern-central India are mainly driven by local aerosol emissions (Fig. $7 \mathrm{~g}$, j). Similar to changes in other characteristics, the main nonlinear effect of combined local and remote emissions is the relative wetting over the northwestern sub-region of the domain, which acts to increase wet event frequency (Fig. 7i, 1).

The substantial nonlinearity in the rainfall response to local and remote aerosols are associated with non-additive responses of the monsoon circulation and other thermodynamic variables (Fig. 8). The strong cooling in the AerosolOnly ensemble over the northern and northwestern subregions of the domain results largely from the influence of remote aerosols (Fig. 8a-c). Although surface temperature is unaltered in the simulations with varying South Asian aerosol emissions alone, historical changes in remote aerosol emissions cause a cooling over the northwestern sub-region, which is further strongly amplified by the combined presence of local and remote aerosol forcings. The occurrence of cooling over regions of enhanced precipitation is suggestive of the modulation of temperature by feedbacks with precipitation rather than due to direct radiative forcing.

Consistent with the relatively large effect of remote aerosols on surface temperature, the weakening of the 850-mb circulation in the Aerosol-Only ensemble appears to occur largely as a response to remote aerosol emissions (Fig. 8d-f). In the Remote Aerosol Emissions simulations, the anomalous easterly winds are shifted relatively south, leading to drier conditions over peninsular India (Figs. 6e, 8e). In addition, southerly flow associated with the anticyclonic circulation over the eastern part of the domain, leads to wetter conditions over northern India (Fig. 7b). In comparison, the effect of local emissions on the circulation is relatively small (Fig. 8d). However, combined local and remote aerosols have the non-linear effect of amplifying the cooling in the northwest that is dominated by remote emissions, resulting in a sharper decrease in the meridional temperature and pressure gradients. The nonlinear circulation response includes an anomalous anticyclonic circulation over central India and an anomalous cyclonic circulation over the Arabian Sea (Fig. 8f). These anomalies shift the remotely-forced anomalous easterlies over peninuslar India northwards, causing drying over central India, and convergence and enhanced rainfall in the southern and western sub-regions of the domain (Fig. 7c). Consistent with the relatively large nonlinear effects on surface temperature and low-level humidity, the pattern of Aerosol-Only changes in vertical stability also closely resemble the pattern of the nonlinear term (Fig. 8g-i).

The closer similarity of anomalies in surface temperature and lower-tropospheric circulation between the AerosolOnly ensemble and the Remote Aerosol Emissions ensemble (compared with the South Asia Aerosol Emissions ensemble) indicates a greater impact of remote aerosols on the regional circulation and thermodynamics. However, the substantial magnitude of the nonlinear temperature and circulation anomalies resulting from the presence of local and remote aerosols suggest that the total Aerosol-Only response in rainfall characteristics is strongly modulated by the non-linear climate response to regional aerosol emissions. These non-linearities could be associated with local feedbacks (such as between temperature and precipitation) and/or large-scale feedbacks (such as that of the coupled Asian Monsoon circulations). Given the comparably higher emission rates over East Asia (Fig. 1), and the large-scale coupling between the South Asian and East Asian monsoons (Day et al. 2015; Ha et al. 2017; Preethi et al. 2017), nonlinearity in the climate response to local and remote aerosols could arise via circulation-precipitation feedbacks between these monsoon systems. For instance, deep tropospheric heating anomalies associated with precipitation increases in one region could influence the upper-tropospheric circulation, which can propagate downstream via, for example, Rossby waves and in turn affect climate in remote regions. Another factor contributing to the non-linearity could be the non-additive effects of different aerosols species over different regions. Such non-linearity was reported by Guo et al. (2016), in particular in the response to black carbon. Given the feedbacks within the climate system, the role of different aerosol species in creating these non-linearities are not straightforward to identify. The magnitude of the nonlinearities highlights the need for simulations similar to those of Guo et al. (2016) to distinguish the effects of individual anthropogenic aerosol species-particularly separating absorbing and scattering aerosols_-and allow for a deeper investigation of the sources of these nonlinearities. 

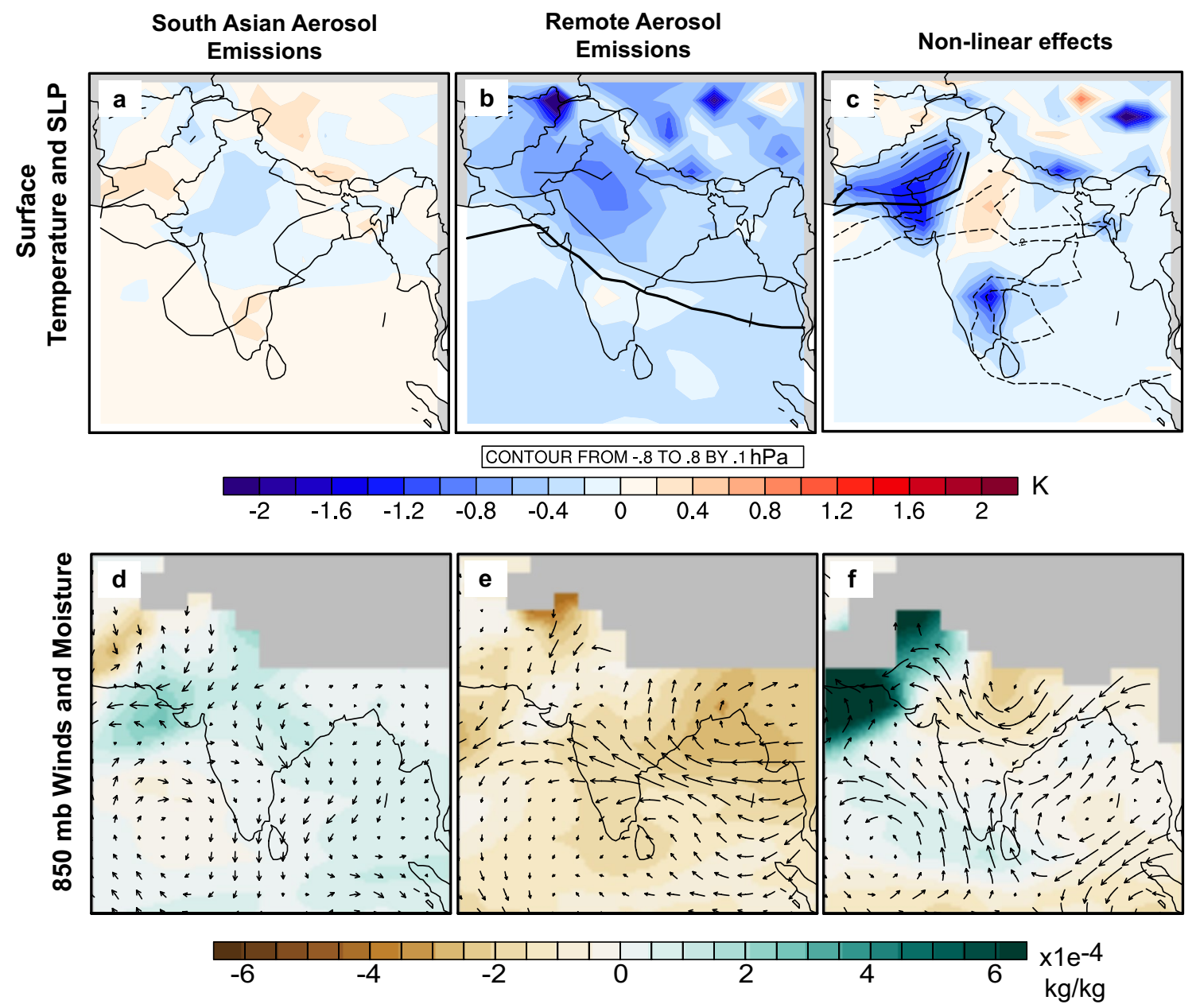

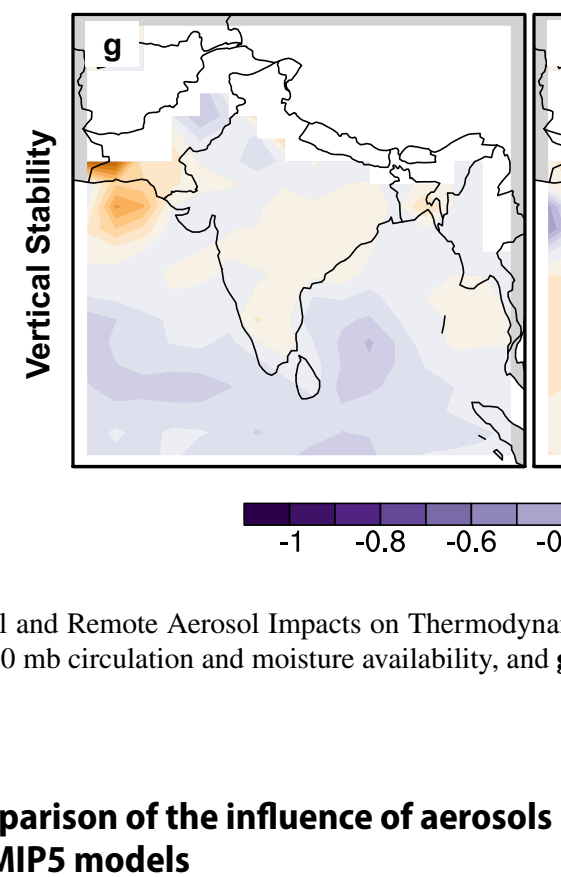
in CMIP5 models

Among the available CMIP5 models, there is disagreement about the influence of aerosols on the ALL-Forcing trends
(Fig. 9). CSIRO-MK3.6.0, the only other model (along with GFDL-CM3) that includes both aerosol indirect effects, consistently exhibits a stronger influence of aerosols on the ALL-Forcing changes in all four rainfall characteristics (relative to other individual forcings; Fig. 9a). In contrast, 


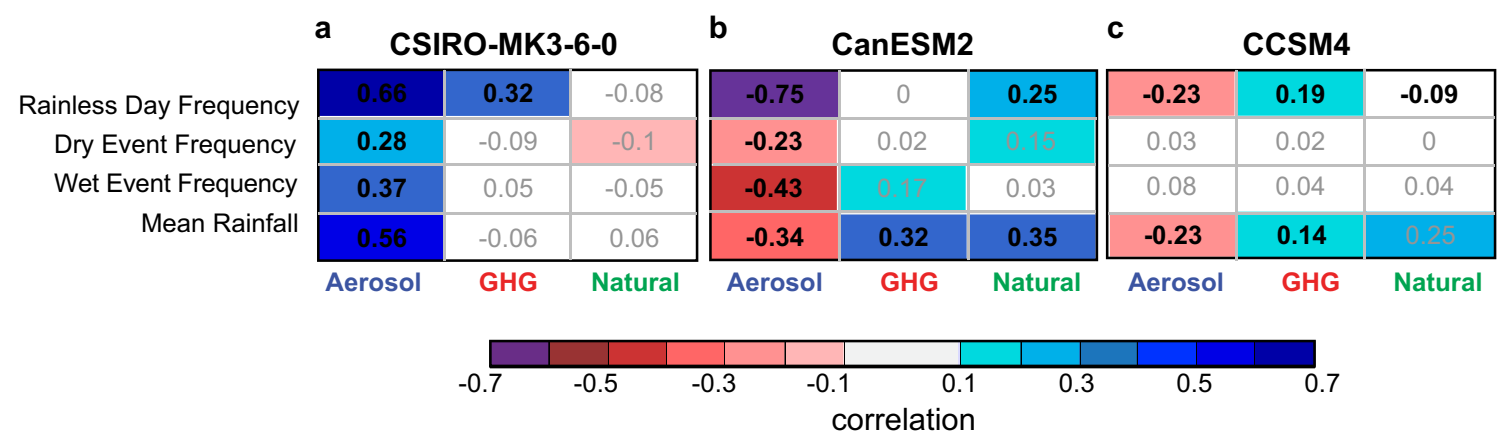

Fig. 9 Uncertainties in the Effects of Individual Forcings on ALLforcing Changes: spatial correlations between ensemble mean changes in the ALL-Forcing and individual forcing experiments in three additional CMIP5 models with multiple ensemble members for the individual forcing experiments. Grey numbers indicate correlations that are insignificant at the 5\% level
CanESM2, which only includes the cloud-albedo effect, exhibits negative correlations between the ALL-Forcing and Aerosol-Only changes, and stronger positive correlations between the ALL-Forcing and Natural-Only changes for mean rainfall, dry event frequency and rainless day frequency (relative to the ALL-Forcing and GHG-Only changes; Fig. 9b). CCSM4, which does not include either indirect effect, does not show substantial and consistent similarties between the ALL-Forcing pattern of changes and either individual forcing pattern of changes (Fig. 9c).

These inter-model differences can be understood in terms of their treatment of aerosol-cloud interactions. Aerosol-cloud interactions are known to be critical for representing historical patterns and trends in surface temperature and precipitation (e.g., Wilcox et al. 2013; Golaz et al. 2013; Levy et al. 2013; Ekman 2014; Wang 2015; Lin et al. 2018). The two models that include a comprehensive treatment of aerosol effects-GFDL-CM3 and CSIRO-MK3.6.0-agree on the relatively larger influence of aerosols on historical changes in these rainfall characteristics (Fig. 9). A recent analysis by Lin et al. (2018) using CMIP5 models (grouped according to their complexity of aerosol treatment) also shows disagreements on the sign of aerosol-induced changes in extreme heavy rainfall over Asia between models that include only direct effects (i.e. CCSM4) and those that include both indirect effects (i.e. GFDL-CM3 and CSIRO-MK3.6.0). They also find that models that include only the first direct effect (i.e. CanESM2) differ considerably from the models that include explicit representations of the cloud-lifetime effect.

Although our analyses of a limited set of models preclude a quantification of the full range of uncertainties, they do highlight the importance of the representation of aerosol effects. While there are still uncertainties in the magnitude of direct radiative effects, aerosol-cloud interactions still represent the largest source of uncertainty in climate models (Boucher et al. 2013). Even among the models that include explicit representations of aerosol-cloud interactions, the representation of various effects is incomplete, and several important processes are not accounted for in coarse resolution models. For instance, the coarse resolution global climate models cannot simulate the effect of increased CCN on mixing and entrainment (Salzmann et al. 2010)—which has contrasting effects on cloud lifetimes compared to the effect of increased $\mathrm{CCN}$ alone (e.g., Ackerman et al. 2004; Xue and Feingold 2006; Zhou and Penner 2017) — potentially leading to an overestimation of aerosol indirect effects (Levy et al. 2013). The interactions between aerosols and deep convection, which can have substantial and potentially contrasting effects on the precipitation distribution in certain regions (Fan et al. 2016), are also not represented in most models (Rotstayn et al. 2015). Further analyses, including additional experiments with cloud-resolving models, can improve the simulation of these effects, and thereby help to elucidate the exact mechanisms by which aerosols can influence daily rainfall events.

\section{Concluding remarks}

In addition to the total seasonal rainfall, changes in such daily-scale rainfall events have implications for agricultural and hydrological systems. For instance, more multiday anomalously low rainfall events or rainless days during the peak growing season can affect the rain-fed agricultural systems prevalent across much of India, which depend on timely and reliable rainfall. Further, multi-day anomalously heavy rainfall events can also damage crops, increase the flooding risk in poorly planned urban systems, strain water management infrastructure, and affect ground water storage (IPCC 2012; Mondal and Mujumdar 2015).

Using a suite of ensemble experiments with the GFDLCM3 climate model, we examine the influence of anthropogenic aerosols and other external climate forcings on peakseason (July-August) mean and daily rainfall characteristics over South Asia. Our results suggest a predominant role of 
anthropogenic aerosols in weakening mean rainfall over India, largely associated with aerosol-cloud interactions, which play a fundamental role during July and August when aerosols and clouds are collocated over the region and when increases in aerosol loading are the strongest in the GFDLCM3 model. These findings extend previous work on rainfall changes during the summer (June-September) monsoon over India (Bollasina et al. 2011; Salzmann et al. 2014; Li et al. 2016; Zhang and Li 2016).

We note three new insights about the drivers of change in daily-scale rainfall events provided by our study:

- Anthropogenic aerosols have a stronger influence on historical changes in wet event frequency, dry event frequency, and rainless days frequency, relative to other external forcings. This influence of anthropogenic aerosols on the dry event and rainless days frequency is larger than their influence on the seasonal mean rainfall.

- Aerosol indirect effects have a substantial influence on changes in dry event and wet event frequency over the areas with the strongest aerosol loading. Despite striking similarity in the response of the large-scale circulation and thermodynamics to changes driven by aerosol indirect effects, direct effects appear to be important in shaping the overall aerosol response of wet events and rainless days over the climatologically drier parts of the subcontinent.

- South Asian aerosols lead to an increase in dry event frequency and decrease in wet frequency, while remote aerosols increase the number of rainy days in the northwestern sub-region. However, the overall response of several rainfall characteristics and their atmospheric environment to aerosols is governed to a large extent by the nonlinear climatic effects of local and remote aerosols.

While recent literature examining daily-scale rainfall has primarily focused on the response to GHG forcing, the potential for anthropogenic aerosols to also play an important role has been mostly overlooked. A few studies have examined the effect of different future aerosol trajectories on certain metrics of rainfall extremes at global and regional scales (Sillmann et al. 2013; Lin et al. 2016). Our study offers new insights by distinguishing the influence of historical aerosol and GHG emissions on daily-scale rainfall characteristics over the historical period, including the roles of direct and indirect aerosol effects, and the roles of local and remote aerosol emissions. Given recent findings on the importance of aerosols for the region's climate, understanding the mechanisms by which aerosols can influence rainfall variability on daily timescales warrants further attention. Further insights will require an expanded archive of singleforcing climate model ensembles, additional simulations with cloud-resolving models, and further development of long-term observations of daily-scale rainfall and of aerosol processes.

We acknowledge a number of caveats in our analysis. First, our analysis of a limited number of climate models does not account for the large inter-model differences in the monsoon response to climate forcings (e.g., Sperber et al. 2013; Sharmila et al. 2015). Additional multi-member ensembles of individual forcing simulations using other climate models that include advanced representations of aerosol physical and chemical processes are required to quantify the full range of uncertainties in the role of historical aerosol emissions. Second, the limited ensemble size might not capture the full range of internal climate variability, which clearly has a substantial influence on the direction and magnitude of historical trends (Deser et al. 2012; Kay et al. 2015). The large spread in the PIcontrol ensemble highlights the potential for internal variability to have a substantial influence on historical trends (Salzmann et al. 2014; Salzmann and Cherian 2015). Although we have compared our single-forcing results with the range of internal variability in the GFDL-CM3 model using the long preindustrial control run, larger ensembles of individual forcing experiments will help to more robustly ascertain this role of internal variability, especially for higher-frequency rainfall variability (Diffenbaugh et al. 2017). Third, the relatively coarse spatial resolution of the model might miss important fine-scale processes that shape the response of such extreme rainfall to forcings (Diffenbaugh et al. 2005; Ashfaq et al. 2009). Fourth, we have not accounted for the influence of changes in natural aerosols such as continental dust, which might modulate short-term rainfall over central India (Vinoj et al. 2014). The CMIP6 experiments (Eyring et al. 2016) could address some of these caveats through the availability of higher resolution models that have improved atmospheric chemistry and physics, as well as larger ensemble sizes.

Along with previous studies highlighting the impact of local and remote anthropogenic aerosols on seasonal-scale rainfall (Ramanathan et al. 2005; Wang et al. 2009; Bollasina et al. 2011; Guo et al. 2016), our study highlights potential mechanisms by which they can impact daily rainfall characteristics of the South Asian summer monsoon. Given current efforts to manage both global GHG increases and regional air quality, our results have important implications for near-term climate adaptation. Although aerosols are projected to decrease globally in the late twenty-first century (Moss et al. 2010; Vuuren et al. 2011), near-term local increases over South Asia could continue to negatively impact societal systems that are strongly dependent on reliable rainfall. In addition, aerosol changes in remote regions (such as East Asia), which can induce circulation changes comparable to or larger than those generated by local aerosols (Bollasina et al. 2014; Chakraborty et al. 2014), may 
also contribute to future rainfall changes over South Asia. Further, our analyses of GHG-Only simulations, as well as many previous studies (e.g., Ashfaq et al. 2009; Stowasser et al. 2009; Krishnan et al. 2016; Kitoh 2017), suggest that continued GHG increases could also result in considerably altered rainfall patterns, particularly when coupled with decreases in aerosol emissions. Considering the influence of different aerosol emissions trajectories over South and East Asia on the regional climate dynamics is therefore critical for effective climate risk management in this highly populated, highly vulnerable region.

Acknowledgements This study is partially supported by the National Science Foundation Grant AGS16-07348 and the Lamont-Doherty Postdoctoral Fellowship. Massimo A. Bollasina was partially supported by the UK-China Research and Innovation Partnership Fund through the Met Office Climate Science for Service Partnership (CSSP) China as part of the Newton Fund. We would like to thank Alexandra Karambelas for helpful discussions. We also thank NOAA Geophysical Fluid Dynamics Laboratory for providing access to the data used in this study. We acknowledge the World Climate Research Programme's Working Group on Coupled Modelling, which is responsible for CMIP, and thank the climate modeling groups (listed in Table 1 of this paper) for producing and making available their model output publicly available. For CMIP, the U.S. Department of Energy's Program for Climate Model Diagnosis and Intercomparison provides coordinating support and led development of software infrastructure in partnership with the Global Organization for Earth System Science Portals. Output for CanESM2 and CSIRO was accessed from https://esgf-node.llnl.gov/ projects/esgf-1lnl/ and for CCSM4 was accessed from https://www. earthsystemgrid.org/dataset/ucar.cgd.ccsm4.cmip5.output.html. We also acknowledge the use of the NCAR Command Language Version 6.3.0 for the analysis and production of maps (Boulder, Colorado: UCAR/NCAR/CISL/TDD. https://doi.org/10.5065/D6WD3XH5). Any data or code used in this manuscript can be made available by contacting the corresponding author (deepti.singh@wsu.edu).

Author contributions DS, MB, and NSD conceived the study. All authors designed the analysis. MB provided the data. DS performed the analysis and all authors wrote the manuscript.

\section{Compliance with ethical standards}

Conflict of interest All authors declare no competing financial interests.

\section{References}

Ackerman AS et al (2004) The impact of humidity above stratiform clouds on indirect aerosol climate forcing. Nature 432:1014. https ://doi.org/10.1038/nature03174

Annamalai H, Slingo JM (2001) Active / break cycles: diagnosis of the intraseasonal variability of the asian summer monsoon. Clim Dyn 18(1):85-102. https://doi.org/10.1007/s003820100161

Arora VK et al (2011) Carbon emission limits required to satisfy future representative concentration pathways of greenhouse gases. Geophys Res Lett. https://doi.org/10.1029/2010GL046270

Ashfaq M et al (2009) Suppression of south Asian summer monsoon precipitation in the 21st century. Geophys Res Lett 36(1):L01704. https://doi.org/10.1029/2008GL036500
Ashfaq M et al (2017) Sources of errors in the simulation of south Asian summer monsoon in the CMIP5 GCMs. Clim Dyn 49(1-2):193-223. https://doi.org/10.1007/s00382-016-3337-7. Accessed 20 June 2017

Bollasina MA, Ming Y, Ramaswamy V (2011) Anthropogenic aerosols and the weakening of the South Asian summer monsoon. Science 334(6055):502-505. http://www.sciencemag.org/conte $\mathrm{nt} / 334 / 6055 / 502$.abstract

Bollasina MA, Ming Y, Ramaswamy V (2013) Earlier onset of the Indian monsoon in the late twentieth century: the role of anthropogenic aerosols. Geophys Res Lett 40(14):3715-3720

Bollasina MA et al. 2014. Contribution of local and remote anthropogenic aerosols to the twentieth century weakening of the South Asian Monsoon. Geophys Res Lett 41(2):680-687

Bolton D (1980) The computation of equivalent potential temperature. Mon Weather Rev 108(7):1046-1053. https://doi. org/10.1175/1520-0493(1980)108\%3C1046:TCOEPT\%3E2.0.CO

Boucher O et al.(2013) Clouds and aerosols. In: Stocker TF et al (eds) Climate change 2013: the physical science basis. Contribution of working group i to the fifth assessment report of the intergovernmental panel on climate change. Cambridge University Press, Cambridge

Chakraborty A, Nanjundiah RS, Srinivasan J (2014) Local and remote impacts of direct aerosol forcing on Asian monsoon. Int J Climatol 34(6):2108-2121. https://doi.org/10.1002/joc.3826

Dash SK et al (2009) Changes in the characteristics of rain events in India. J Geophys Res 114(D10):D10109. https://doi. org/10.1029/2008JD010572

Dave P, Bhushan M, Venkataraman C (2017) Aerosols cause intraseasonal short-term suppression of Indian monsoon rainfall. Sci Rep 7(1):17347. https://doi.org/10.1038/s41598-017-17599-1

Day JA, Fung I, Risi C (2015) Coupling of South and East Asian monsoon precipitation in July-August. J Clim 28(11):4330-4356. https://doi.org/10.1175/JCLI-D-14-00393.1

Deser C et al (2012) Communication of the role of natural variability in future North American climate. Nat Clim Change 2(11):775-779

Diffenbaugh NS et al (2005) Fine-scale processes regulate the response of extreme events to global climate change. Proc Natl Acad Sci USA 102(44):8

Diffenbaugh NS et al (2017) Quantifying the influence of global warming on unprecedented extreme climate events. Proc Natl Acad Sci 114(19):4881-4886. http://www.pnas.org/content/114/19/4881. abstract

Donner LJ et al (2011) The dynamical core, physical parameterizations, and basic simulation characteristics of the atmospheric component AM3 of the GFDL global coupled model CM3. J Clim 24(13):3484-3519. https://doi.org/10.1175/2011JCLI3955.1

Ekman AML (2014) Do sophisticated parameterizations of aerosolcloud interactions in CMIP5 models improve the representation of recent observed temperature trends? J Geophys Res Atmos 119:817-832

Eyring V, Bony S, Meehl GA, Senior CA, Stevens B, Stouffer RJ, Taylor KE (2016) Overview of the coupled model intercomparison Project Phase 6 (CMIP6) experimental design and organization. Geosci Model Dev 9:1937-1958. https://doi.org/10.5194/ gmd-9-1937-2016

Fan J et al (2012) Aerosol impacts on clouds and precipitation in eastern China: results from bin and bulk microphysics. J Geophys Res Atmos. https://doi.org/10.1029/2011JD016537

Fan J et al (2013) Microphysical effects determine macrophysical response for aerosol impacts on deep convective clouds. Proc Natl Acad Sci 110(48):E4581-E4590. https://doi.org/10.1073/ pnas. 1316830110

Fan J et al (2016) Review of aerosol-cloud interactions: mechanisms, significance, and challenges. J Atmos Sci 73(11):4221-4252. https ://doi.org/10.1175/JAS-D-16-0037.1 
Fischer EM, Knutti R (2015) Anthropogenic contribution to global occurrence of heavy-precipitation and high-temperature extremes. Nat Clim Change 5(6):560-564

Forster $\mathrm{P}$ et al (2007) Changes in atmospheric constituents and in radiative forcing. In: Climate change 2007: The physical science basis. contribution of working group $i$ to the fourth assessment report of the intergovernmental panel on climate change. In: MT and HLM, Solomon S, Qin D, Manning M, Chen Z, Marquis M, Averyt KB (eds) Cambridge University Press, Cambridge

Gadgil S, Gadgil S (2006) The Indian monsoon, GDP and agriculture. http://www.epw.in/special-articles/indian-monsoon-gdp-and-agric ulture.html

Gadgil S, Kumar KR (2006) The Asian monsoon-agriculture and economy. In Wang B (ed) The Asian monsoon. Springer/Praxis Publishing Co., Berlin

Gent PR et al (2011) The community climate system model version 4. J Clim 24(19):4973-4991. https://doi.org/10.1175/2011JCLI4083.1

Golaz JC et al (2011) Sensitivity of the aerosol indirect effect to subgrid variability in the cloud parameterization of the GFDL atmosphere general circulation model AM3. J Clim 24(13):3145-3160

Golaz JC, Golaz JC, Levy, H (2013) Cloud tuning in a coupled climate model: Impact on 20th century warming. Geophys Res Lett 40(10):2246-2251

Gornall $\mathbf{J}$ et al (2010) Implications of climate change for agricultural productivity in the early twenty-first century. Philos Trans R Soc Lond B Biol Sci 365(1554):2973-2989. http://www.ncbi.nlm.nih. gov/pubmed/20713397

Granier C et al (2011) Evolution of anthropogenic and biomass burning emissions of air pollutants at global and regional scales during the 1980-2010 period. Clim Change 109(1):163. https://doi. org/10.1007/s10584-011-0154-1

Guhathakurta P, Rajeevan M (2008) Trends in the rainfall pattern over India. Int J Climatol 28(11):1453-1469

Guhathakurta P, Sreejith OP, Menon PA (2011) Impact of climate change on extreme rainfall events and flood risk in India. J Earth Syst Sci 120(3):359. https://doi.org/10.1007/s12040-011-0082-5

Guo L, Turner AG, Highwood EJ (2015) Impacts of 20th century aerosol emissions on the South Asian monsoon in the CMIP5 models. Atmos Chem Phys 15(11):6367-6378. http://www.atmos-chemphys.net/15/6367/2015/

Guo L, Turner AG, Highwood EJ (2016) Local and remote impacts of aerosol species on Indian summer monsoon rainfall in a GCM. J Clim 29(19):6937-6955. https://doi.org/10.1175/ JCLI-D-15-0728.1

Ha K-J et al (2017) Linkages between the South and East Asian summer monsoons: a review and revisit. Clim Dyn. https://doi. org/10.1007/s00382-017-3773-Z

Hurley JV, Boos WR (2014) A global climatology of monsoon lowpressure systems. Q J R Meteorol Soc 141:1049-1064

IPCC (2012) Managing the risks of extreme events and disasters to advance climate change adaptation. In: Field CB, Barros V, Stocker TF, Qin D, Dokken DJ, Ebi KL, Mastrandrea MD, Mach KJ, Plattner G-K, Allen SK, Tignor M, Midgley PM (eds) A special report of working groups I and II of the intergovernmental panel on climate change. Cambridge University Press, Cambridge, UK, New York, NY, USA, p 582

Kay JE et al (2015) The community earth system model (CESM) large ensemble project: a community resource for studying climate change in the presence of internal climate variability. Bull Am Meteorol Soc 96(8):1333-1349. https://doi.org/10.1175/BAMSD-13-00255.1

Kitoh A (2017) The Asian monsoon and its future change in climate models: a review. J Meteorol Soc Jpn Ser II 95(1):7-33. https:// doi.org/10.2151/jmsj.2017-002
Koren I, Dagan G, Altaratz O (2014) From aerosol-limited to invigoration of warm convective clouds. Science 344(6188):1143-1147

Krishnamurthy V, Shukla J (2008) Seasonal persistence and propagation of intraseasonal patterns over the Indian summer monsoon region. Clim Dyn 30:353-369

Krishnan R et al (2016) Deciphering the desiccation trend of the South Asian monsoon hydroclimate in a warming world. Clim Dyn 47(3-4):1007-1027. https://doi.org/10.1007/s00382-015-2886-5

Lamarque J-F et al (2010) Historical (1850-2000) gridded anthropogenic and biomass burning emissions of reactive gases and aerosols: methodology and application. Atmos Chem Phys 10(15):7017-7039

Lau WKM, Kim K-M (2010) Fingerprinting the impacts of aerosols on long-term trends of the Indian summer monsoon regional rainfall. Geophys Res Lett 37(16):L16705. https://doi.org/10.1029/2010G L043255

Levy $\mathrm{H}$ et al (2013) The roles of aerosol direct and indirect effects in past and future climate change. J Geophys Res Atmos 118(10):4521-4532. https://doi.org/10.1002/jgrd.50192

Li X et al (2015) Mechanisms of Asian summer monsoon changes in response to anthropogenic forcing in CMIP5 models. J Clim 28(10):4107-4125. https://doi.org/10.1175/JCLI-D-14-00559.1

$\mathrm{Li} \mathrm{Z} \mathrm{et} \mathrm{al} \mathrm{(2016)} \mathrm{Aerosol} \mathrm{and} \mathrm{monsoon} \mathrm{climate} \mathrm{interactions} \mathrm{over} \mathrm{Asia.}$ Rev Geophys 54(4):866-929. https://doi.org/10.1002/2015R G000500

Lin L et al (2016) Sensitivity of precipitation extremes to radiative forcing of greenhouse gases and aerosols. Geophys Res Lett 43(18):9860-9868. https://doi.org/10.1002/2016GL070869

Lin L et al (2018) Changes in extreme rainfall over India and China attributed to regional aerosol-cloud interaction during the late 20th century rapid industrialization. Geophys Res Lett. https:// doi.org/10.1029/2018GL078308

Lu Z, Zhang Q, Streets DG (2011) Sulfur dioxide and primary carbonaceous aerosol emissions in China and India, 1996-2010. Atmos Chem Phys 11(18):9839-9864. https://www.atmos-chem-phys. net/11/9839/2011/

Ma X, von Salzen K, Cole J (2010) Constraints on interactions between aerosols and clouds on a global scale from a combination of MODIS-CERES satellite data and climate simulations. Atmos Chem Phys 10(20):9851-9861. https://www.atmos-chem-phys. net/10/9851/2010/

Mandke SK et al (2007) Simulated changes in active/break spells during the Indian summer monsoon due to enhanced $\mathrm{CO} 2$ concentrations: assessment from selected coupled atmosphere-ocean global climate models. Int J Climatol 27(7):837-859. https://doi. org/10.1002/joc. 1440

Min S-K et al (2011) Human contribution to more-intense precipitation extremes. Nature 470(7334):378-381

Ming Y et al (2006) A new parameterization of cloud droplet activation applicable to general circulation models. J Atmos Sci 63(4):13481356. https://doi.org/10.1175/JAS3686.1

Ming Y et al (2007) Modeling the Interactions between aerosols and liquid water clouds with a self-consistent cloud scheme in a general circulation model. J Atmos Sci 64(4):1189-1209. https://doi. org/10.1175/JAS3874.1

Mondal A, Mujumdar PP (2015) Regional hydrological impacts of climate change: implications for water management in India. Proc IAHS 366:34-43. https://doi.org/10.5194/piahs-366-34-2015

Moss RH et al (2010) The next generation of scenarios for climate change research and assessment. Nature, 463(7282):747-756. https://doi.org/10.1038/nature08823

Ning L, Liu J, Sun W (2017) Influences of volcano eruptions on Asian summer monsoon over the last 110 years. Sci Rep 7:3-8. https:// doi.org/10.1038/srep42626 
Pai DS et al (2015) Analysis of the daily rainfall events over India using a new long period (1901-2010) high resolution $\left(0.25^{\circ} \times 0.25^{\circ}\right)$ gridded rainfall data set. Clim Dyn 45(3-4):755-776. https://doi. org/10.1007/s00382-014-2307-1

Persad GG et al (2017) Competing atmospheric and surface-driven impacts of absorbing aerosols on the east asian summertime climate. J Clim 30(22):8929-8949. https://doi.org/10.1175/ JCLI-D-16-0860.1

Preethi B et al (2017) Variability and teleconnections of South and East Asian summer monsoons in present and future projections of CMIP5 climate models. Asia Pac J Atmos Sci 53(2):305-325. https://doi.org/10.1007/s13143-017-0034-3

Pu B, Ginoux P (2016) The impact of the Pacific Decadal Oscillation on springtime dust activity in Syria. Atmos Chem Phys 16(21):13431-13448

Rajeevan M, Gadgil S, Bhate J (2010) Active and break spells of the Indian summer monsoon. J Earth Syst Sci 119(3):229-247. https ://doi.org/10.1007/s12040-010-0019-4

Ramanathan V et al (2001) Aerosols, climate, and the hydrological cycle. Science 294(5549):2119-2124. http://www.sciencemag .org/content/294/5549/2119.abstract

Ramanathan V et al (2005) Atmospheric brown clouds: Impacts on South Asian climate and hydrological cycle. Proc Natl Acad Sci USA 102(15):5326-5333. http://www.pnas.org/conte nt/102/15/5326.abstract

Rosenfeld D et al (2008) Flood or drought: how do aerosols affect precipitation? Science 321(5894):1309LP-1313. http://science.scien cemag.org/content/321/5894/1309.abstract

Rotstayn LD et al (2012) Aerosol- and greenhouse gas-induced changes in summer rainfall and circulation in the Australasian region: a study using single-forcing climate simulations. Atmos Chem Phys 12(14):6377-6404. https://www.atmos-chem-phys. net/12/6377/2012/

Rotstayn LD et al (2014) Declining aerosols in CMIP5 projections: effects on atmospheric temperature structure and midlatitude jets. J Clim 27(18):6960-6977

Rotstayn LD, Collier MA, Luo JJ (2015) Effects of declining aerosols on projections of zonally averaged tropical precipitation. Environ Res Lett 10(4):044018

Roxy MK et al (2017) A threefold rise in widespread extreme rain events over central India. Nat Commun 8:708. https://doi. org/10.1038/s41467-017-00744-9

Salinger MJ, Griffiths GM (2001) Trends in New Zealand daily temperature and rainfall extremes. Int J Climatol 21(12):1437-1452. https://doi.org/10.1002/joc.694

Salzmann M, Cherian R (2015) On the enhancement of the Indian summer monsoon drying by Pacific multidecadal variability during the latter half of the twentieth century. J Geophys Res Atmos 120:9103-9118

Salzmann M et al (2010) Two-moment bulk stratiform cloud microphysics in the GFDL AM3 GCM: description, evaluation, and sensitivity tests. Atmos Chem Phys 10(16):8037-8064

Salzmann M, Weser H, Cherian R (2014) Robust response of Asian summer monsoon to anthropogenic aerosols in CMIP5 models. J Geophys Res Atmos 119(19):11,321-11,337. https://doi. org/10.1002/2014JD021783

Sharmila S et al (2015) Future projection of Indian summer monsoon variability under climate change scenario: an assessment from CMIP5 climate models. Glob Planet Change 124:62-78
Sillmann J et al (2013) Aerosol effect on climate extremes in Europe under different future scenarios. Geophys Res Lett 40(10):2290-2295

Singh D et al (2014) Observed changes in extreme wet and dry spells during the South Asian summer monsoon season. Nat Clim Change 4(April): $1-6$

Smith SJ et al (2011) Anthropogenic sulfur dioxide emissions: 1850 2005. Atmos. Chem. Phys. 11(3):1101-1116. https://www.atmos -chem-phys.net/11/1101/2011/

Sperber KR et al (2013) The Asian summer monsoon: an intercomparison of CMIP5 vs. CMIP3 simulations of the late 20th century. Clim Dyn 41(9-10):2711-2744. https://doi.org/10.1007/s0038 2-012-1607-6

Stanberry L (2013) Permutation test. In: W. Dubitzky et al (eds) Encyclopedia of systems biology. Springer, New York, pp 1678. https ://doi.org/10.1007/978-1-4419-9863-7_1186

Stowasser M, Annamalai H, Hafner J (2009) Response of the south Asian summer monsoon to global warming: mean and synoptic systems*. J Clim 22(4):1014-1036. https://doi.org/10.1175/2008J CLI2218.1

Taylor KE, Stouffer RJ, Meehl GA (2012) An overview of CMIP5 and the experiment design. Bull Am Meteorol Soc 93(4):485-498. https://doi.org/10.1175/BAMS-D-11-00094.1

Turner AG, Annamalai H (2012) Climate change and the South Asian summer monsoon. Nat Clim Change 2(August):587-595. https:// doi.org/10.1038/nclimate1495

van Vuuren DP et al (2011) The representative concentration pathways: an overview. Clim Change 109(1):5. https://doi.org/10.1007/s1058 4-011-0148-z

Vinnarasi R, Dhanya CT (2016) Changing characteristics of extreme wet and dry spells of Indian monsoon rainfall. J Geophys Res Atmos 121(5):2146-2160

Vinoj V et al (2014) Short-term modulation of Indian summer monsoon rainfall by West Asian dust. Nat Geosci 7(4):308-313

Vuuren DP et al (2011) A special issue on the RCPs. Clim Change 109(1):1-4

Wang C (2015) Anthropogenic aerosols and the distribution of past large-scale precipitation change. Geophys Res Lett 42(24):10876-10884

Wang C et al (2009) Impact of anthropogenic aerosols on Indian summer monsoon. Geophys Res Lett 36(21):L21704. https://doi. org/10.1029/2009GL040114

Wilcox LJ, Highwood EJ, Dunstone NJ (2013) The influence of anthropogenic aerosol on multi-decadal variations of historical global climate. Environ Res Lett 8(2):024033

Xue H, Feingold G (2006) Large-eddy simulations of trade wind cumuli: investigation of aerosol indirect effects. J Atmos Sci 63(6):1605-1622. http://journals.ametsoc.org/doi/abs/10.1175/ JAS3706.1

Yatagai A et al (2012) APHRODITE: constructing a long-term daily gridded precipitation dataset for asia based on a dense network of rain gauges. Bull Am Meteorol Soc 93(9):1401-1415. https://doi. org/10.1175/BAMS-D-11-00122.1

Zhang L, Li T (2016) Relative roles of anthropogenic aerosols and greenhouse gases in land and oceanic monsoon changes during past 156 years in CMIP5 models. Geophys Res Lett 43:5295-5301

Zhou C, Penner JE (2017) Why do general circulation models overestimate the aerosol cloud lifetime effect? A case study comparing CAM5 and a CRM. Atmos Chem Phys 17(1):21-29 